\title{
Modeling of Forced Flow-thermal Gradient CVI: Effects of Control Parameters and Processing Schemes on a Densification
}

\section{Pengfei WANG}

Tsinghua University

Shengfeng Luo ( $\sim$ luosf@mail.ustc.edu.cn )

Tsinghua University Department of Engineering Physics

Hui ZHANG

Tsinghua University

Song ZHANG

Tsinghua University

\section{Lili ZHENG}

Tsinghua University

\section{Research Article}

Keywords: ceramic matrix composite, chemical vapor infiltration, deposition, modeling

Posted Date: October 14th, 2020

DOl: https://doi.org/10.21203/rs.3.rs-91048/v1

License: (c) (1) This work is licensed under a Creative Commons Attribution 4.0 International License. Read Full License 


\title{
Modeling of forced flow-thermal gradient CVI: effects of control parameters and processing schemes on a densification
}

\author{
Pengfei WANG ${ }^{a}$, Shengfeng LUO ${ }^{a,}{ }^{*}$, Hui ZHANG ${ }^{a}$, Song ZHANG ${ }^{b}$, Lili ZHENG $^{c}$ \\ ${ }^{a}$ Department of Engineering Physics, Tsinghua University, Beijing, 100084, China \\ ${ }^{b}$ Institute for Aero Engine, Tsinghua University, Beijing, 100084, China \\ ${ }^{c}$ School of Aerospace Engineering, Tsinghua University, Beijing, 100084, China
}

\begin{abstract}
A two-channel temperature-control infiltration reactor aiming at fabricating thicker and more uniform composites was designed. Unsteady numerical simulations containing hydrodynamics, mass transfer, heat transfer and pore structure evolution were carried out. By analyzing the effects of concentration, velocity and temperature on the porosity distribution, different densification schemes were proposed and compared. Results show that a preform of thickness $0.04 \mathrm{~m}$ and initial porosity 0.8 can be densified to a uniform and compact one with the maximum porosity of 0.1 within 300 hours through the three-step densification scheme. This scheme not only assures a low and uniform porosity over the whole preform but also avoids the huge pumping pressure which may cause the preform cracking.
\end{abstract}

Keywords: ceramic matrix composite; chemical vapor infiltration; deposition; modeling

\section{Introduction}

The ceramic matrix composites (CMCs) have continued to be of special concern that promises high safety and economic benefits in the fields of aeronautic and aerospace due to their excellent thermal and mechanical properties [1-2]. Its main fabrication technique is chemical vapor infiltration (CVI), whereby silicon carbide

\footnotetext{
* Corresponding author.

E-mail: luosf@mail.ustc.edu.cn
} 
(SiC) matrix infiltrates into the porous preform and deposits on the fiber to form fiber-reinforced composites [3]. The most widely used CVI technique is isothermal isobaric CVI (ICVI), in which the densification is carried out at uniform temperature and the reactant gases are transported by concentration-gradients-induced diffusion. The ICVI was first introduced in the 1960s [4], and it is still widely used today [5-8] because it requires a rather simple technology and procedure. The preforms with complex shapes can be easily densified in the same run. However, its densification rate is very low, and the infiltration always lasts for hundreds of hours [7] due to the limitation of diffusion transport mode; besides, the surface of porous preform is often sealed due to overcoating, while the inner preform is still coarse, thus the infiltration process must be interrupted to machine impermeable skin [9].

A forced flow and an appropriate temperature gradient may fix the problems of transportation limitation and nonuniform deposition. Actually, since the 1980s the forced flow-thermal gradient CVI (F-TGCVI) has been developed to improve the densification quality [10-12]. The F-TGCVI reactor mainly consists of a bottom water-cooled holder and a top hot furnace. The reactant gases are forced into the fibrous preform under pressure and flowed from the cooled side to the hot side. The rapid flow can significantly accelerate the densification, for instance, preform densification that previously required weeks to densify now requires $\sim 24 \mathrm{~h}[12]$. The highest deposition rate of $3 \mu \mathrm{m} / \mathrm{h}$ was reported in Ref. [13]. The initial steep temperature gradient makes the deposition mainly occur at the hot portion of the preform, which will increase the density and thermal conductivity of the preform. Consequently, the hot region expands progressively from the top hot side to the bottom cooled side of the preform, so does the densification. This deposition feature avoids the frequent interruption of machining impermeable skin, but with the 
densification going on, the top hot side of the preform may be quite dense while other portions are still coarse. For instance, the coating thickness is about $8 \mu \mathrm{m}$ at the cold side while $22-24 \mu \mathrm{m}$ at the hot side [14]. This phenomenon gives rise to two problems. One is that the preform cannot be thick. The densified preform reported in Refs. [13-16] are quite thin, only $0.64-1.27 \mathrm{~cm}$. The other one is that as the infiltration progressed, the back pressure increased as the pores in the preform were filled by the deposited matrix, the back pressure increased from the initial $3.4 \mathrm{KPa}$ to a final 170 $\mathrm{KPa}$ in Ref. [13]. The huge pump pressure may cause preform cracking [17].

In order to solve these problems, we designed a two-channel F-TGCVI reactor, which is expected to obtain a thicker and more uniform composite material. Since running timescale experiments to test this design or optimize the parameters can be very expensive [18], the numerical simulation might be an economically viable way. In F-TGCVI, the control parameters, such as temperature, pressure, the gas composition and the flow rate, all affect chemical reaction and furtherly change the pore structure. The evolution of pore structure, in turn, will affect the species transport and temperature distribution. Therefore, it is not appropriate to simulate the infiltration process with an oversimplified mathematic model or assumption of a steady state of temperature and concentration [19-20]. In the present paper, a two-dimensional unsteady numerical simulation was carried out, in which hydrodynamics, mass transfer, heat transfer and pore structure evolution were considered. The effects of inlet reagent concentration, inlet gas velocity and temperature on the porosity distribution were analyzed and an improved three-step densification scheme was also given.

\section{Numerical scheme}


In the present paper, precursor methyltrichlorosilane $\left(\mathrm{CH}_{3} \mathrm{SiCl}_{3}, \mathrm{MTS}\right)$, carrier gas hydrogen and carbon fiber are adopted to fabricate $\mathrm{C}_{f} / \mathrm{SiC}$ composites through the two-channel F-TGCVI reactor. Since the complex relationships among the time-dependent variables, such as chemical reaction, concentration, temperature and porosity, will make it difficult to model the deposition in the preform, some necessary assumptions are considered:

- The pyrolysis of MTS is regarded as a first order reaction [21-22], and the reaction is simplified as $\mathrm{CH}_{3} \mathrm{SiCl}_{3} \rightarrow \mathrm{SiC}_{(\mathrm{s})}+3 \mathrm{HCl}$. The heat generation by the chemical reaction is neglected.

- The porosity is considered uniform in the porous preform before infiltration, and the model of the surface area distribution between and within bundles proposed in Ref. [19] is also applicable to this work.

- All of the gases are considered as incompressible ideal gas, and the variation of their certain properties, such as density, dynamic viscosity, diffusion coefficient with temperature are neglected.

\subsection{Physical model}

The physical model, as shown in Fig. 1, contains two rectangle channels (the horizontal one $0.1 \times 0.5 \mathrm{~m}^{2}$, the vertical one $0.1 \times 0.25 \mathrm{~m}^{2}$ ) and a $0.1 \times 0.04 \mathrm{~m}^{2}$ rectangle porous preform locating at the junction. $\mathrm{A}, \mathrm{B}$ and $\mathrm{C}$ are velocity inlet or pressure outlet, reactor walls are thermal insulation and a certain temperature is assigned to the top and bottom edges of the preform (in practice, this can be achieved by the focused IR heating technology). Based on this two-channel F-TGCVI reactor, the flow control and the temperature control can be closely matched to optimize the deposition process, thus fabricating thick and uniform composite, simultaneously protecting the fiber preform from cracking. 


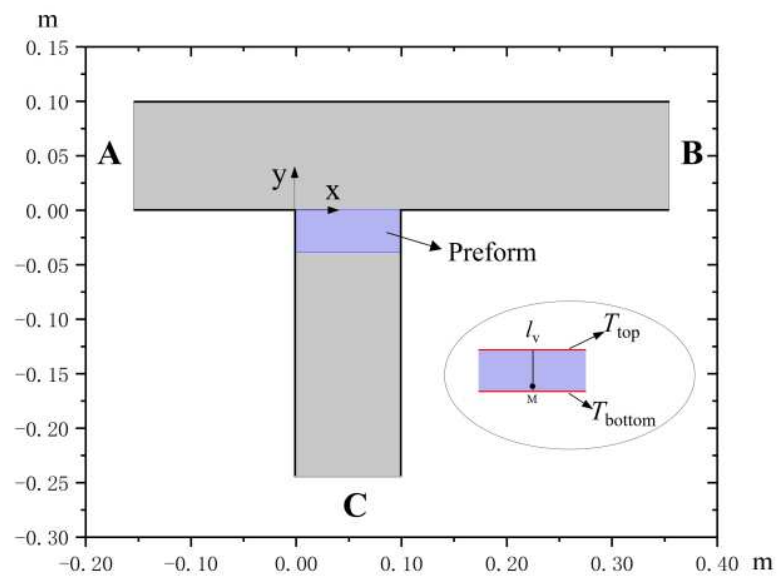

Fig. 1 Schematic of physical model. For the convenience of results display, the vertical midline of preform is marked as $l_{\mathrm{v}}$, the coordinate origin is set at the top-left end point of the preform and the point $(0.05,-0.0374)$ is marked as $\mathrm{M}$, the temperature at the top and bottom edges of the preform are marked as $T_{\text {top }}$ and $T_{\text {bottom, }}$, respectively.

\subsection{Mass transport}

According to mass conservation, chemical species transport through diffusion and convection can be expressed as [23]:

$$
\frac{\partial \varepsilon c_{i}}{\partial t}+\mathbf{u} \cdot \nabla c_{i}-\nabla \cdot D_{\text {eff }} \nabla c_{i}=R_{i}
$$

where $\varepsilon$ denotes the porosity of preform; $c_{i}$ is the concentration of species $i, \mathrm{~mol} / \mathrm{m}^{3} ; t$ is the infiltration time, $\mathrm{s} ; \mathbf{u}$ is the velocity field, $\mathrm{m} / \mathrm{s} ; D_{\text {eff }}$ denotes the effective diffusion coefficient, $\mathrm{m}^{2} / \mathrm{s}, \quad D_{\text {eff }}=\varepsilon D_{A B} / \tau, \tau$ is the tortuosity factor, $\tau=\left(\varepsilon_{0}-0.03\right) /(\varepsilon-0.03){ }^{0.95}[6], D_{A B}$ is the Fick diffusion coefficient [24],

$$
D_{A B}=\frac{10^{-7} T^{1.75}\left(1 / M_{A}+1 / M_{B}\right)^{1 / 2}}{p\left[\Sigma V_{A}^{1 / 3}+\Sigma V_{B}^{1 / 3}\right]^{2}}
$$

the subscript $A, B$ represents MTS and $\mathrm{H}_{2} ; T$ is the temperature, $\mathrm{K} ; M$ is the molecular weight, $\mathrm{kg} / \mathrm{mol} ; p$ is the absolute pressure, atm; $\sum V$ is the diffusion volume, a sum of atomic volumes in each molecule. $R_{i}$ is the reaction rate expression for the species $i$, $\mathrm{mol} /\left(\mathrm{m}^{3} \cdot \mathrm{s}\right)$, for the reagent (MTS, $\left.i=1\right)$, for example, $R_{1}$ can be expressed as: 


$$
R_{1}=-k_{\mathrm{s}} c_{1} S_{\mathrm{V}}
$$

$k_{\mathrm{s}}$ is the reaction rate constant, $\mathrm{m} / \mathrm{s}, k_{\mathrm{s}}=k_{0} \exp \left(-E_{\mathrm{r}} / \mathrm{R} T\right), k_{0}$ is the preexponential factor, $\mathrm{m} / \mathrm{s}, E \mathrm{r}$ is the activation energy, $\mathrm{J} / \mathrm{mol}$, and $\mathrm{R}$ is the gas constant, $\mathrm{J} /(\mathrm{K} \cdot \mathrm{mol}) ; c_{1}$ is the concentration of MTS, $\mathrm{mol} / \mathrm{m}^{3}$, initial MTS concentration $c_{1,0}=\chi p / \mathrm{RT}, \chi$ is the molar fraction of MTS; $S_{\mathrm{v}}$ is the surface area per unit volume, $1 / \mathrm{m}$, $S_{\mathrm{V}}=2 / r_{0} \sqrt{\left(1-\varepsilon_{0}\right) / \varepsilon_{0}} \sqrt{1-\varepsilon \varepsilon}[19], r_{0}$ and $\varepsilon_{0}$ are the initial pore radius (m) and porosity, respectively. The deposition of $\mathrm{SiC}(i=2)$ causes the progressive plugging of the preform, therefore, the preform structural evolution can be written as:

$$
\frac{\mathrm{d} \varepsilon}{\mathrm{d} t}=-\frac{M_{2}}{\rho_{2}} k_{\mathrm{s}} c_{1} S_{\mathrm{V}}
$$

$M_{2}$ is the molecular weight of $\mathrm{SiC}, \mathrm{kg} / \mathrm{mol} ; \rho_{2}$ is the density of $\mathrm{SiC}, \mathrm{kg} / \mathrm{m}^{3}$.

\subsection{Flow}

Flow in the free and porous domain are modeled using the Navier-Stokes equation and modified Navier-Stokes equation (Brinkmann equation) [25], respectively,

$$
\begin{gathered}
\rho \frac{\partial \mathbf{u}}{\partial t}=\nabla \cdot\left[-p \mathbf{I}+\mu \nabla \mathbf{u}+\nabla \mathbf{u}^{T}\right] \\
\frac{\rho}{\varepsilon} \frac{\partial \mathbf{u}}{\partial t}=-\nabla p+\nabla \cdot\left[\frac{1}{\varepsilon}\left(\mu \nabla \mathbf{u}+\nabla \mathbf{u}^{T}-\frac{2}{3} \mu \nabla \cdot \mathbf{u} \mathbf{I}\right)\right]-\frac{Q_{\mathrm{m}}}{\varepsilon^{2}} \mathbf{u}-\frac{\mu}{\kappa} \mathbf{u}
\end{gathered}
$$

where $\rho$ is the density of gas mixture, $\mathrm{kg} / \mathrm{m}^{3} ; \mu$ is the dynamic viscosity of gas mixture, $\mathrm{kg} /(\mathrm{m} \cdot \mathrm{s}) ; \mathbf{I}$ denotes the identity matrix; $Q_{\mathrm{m}}$ denotes the mass deposit, $\mathrm{kg} /\left(\mathrm{m}^{3} \cdot \mathrm{s}\right)$, $Q_{\mathrm{m}}=\rho \nabla \cdot \mathbf{u} ; \kappa$ is the permeability, $\mathrm{m}^{2}, \quad \kappa=D_{p}^{2} \varepsilon^{3} /\left[1501-\varepsilon^{2}\right][25], D_{\mathrm{p}}$ is the average particle diameter, $\mathrm{m}, D_{p}=4 \varepsilon / S_{\mathrm{V}}[25]$.

\subsection{Heat transfer}

According to local thermal equilibrium, heat transfer equation in the porous domain is [26]: 


$$
\rho C_{p_{\text {eff }}} \frac{\partial T}{\partial t}+\rho C_{p} \mathbf{u} \cdot \nabla T+\nabla \cdot \mathbf{q}=Q
$$

where $\left(\rho C_{p}\right)_{\text {eff }}$ is the effective volumetric heat capacity, consisting of porous medium term and gas mixture term, $\left(\rho C_{p}\right)_{\text {eff }}=(1-\varepsilon) \rho_{\mathrm{p}} C_{p, \mathrm{p}}+\varepsilon \rho C_{p} ; \mathbf{q}$ is the conductive heat flux, W/m, $\mathbf{q}=-k_{\text {eff }} \nabla T, k_{\text {eff }}$ is the effective thermal conductivity, $\mathrm{W} /(\mathrm{m} \cdot \mathrm{K})$, $k_{\text {eff }}=1-\varepsilon k_{\mathrm{p}}+\varepsilon k$, the 'irradiative conductivity' [27-28] is added to the $k_{\mathrm{p}} ; Q$ is the heat source, $\mathrm{W} / \mathrm{m}$. Heat transfer equation in the free domain is similar except ruling out the porous medium term.

\subsection{Numerical solver}

The COMSOL Multiphysics 5.5 was adopted to conduct the present two-dimension transient Multiphysics modeling. The transport of diluted species, Brinkman equation and heat transfer in porous media modules were activated to deal with the flow, mass transport and heat transfer problems, respectively. The issue of porosity evolution was settled by defining custom variables and a partial differential equation. A physics-controlled mesh (the element size is finer) was built, hour was selected as time unit and time step was $0.1 \mathrm{~h}$. The requirement of mesh and time step independence were all met. Parameters used in the present simulation are summarized in Table 1.

Table 1 List of parameters used in the simulation

\begin{tabular}{llll}
\hline Parameter & Value & Parameter & Value \\
\hline Total pressure $p$ & $10 \mathrm{kPa}$ & Initial porosity $\varepsilon_{0}$ & 0.8 \\
$\mathrm{H}_{2} / \mathrm{MTS}$ molar ratio $\chi$ & 6 & Initial pore radius $r_{0}$ & $7 \times 10^{-6} \mathrm{~m}$ \\
Gas flow $F$ & $1 \times 10^{-4} \mathrm{~m}^{3} / \mathrm{s}$ & Specific Heat of gas $C_{p}$ & $14990 \mathrm{~J} /(\mathrm{kg} \cdot \mathrm{K})$ \\
Dynamic viscosity $\mu$ & $5.4641 \times 10^{-4} \mathrm{~Pa} \cdot \mathrm{s}$ & Specific Heat of preform $C_{p, \mathrm{p}}$ & $2020 \mathrm{~J} /(\mathrm{kg} \cdot \mathrm{K})$ \\
Density of gas $\rho$ & $29.596 \mathrm{~kg} / \mathrm{m}^{3}$ & Thermal conductivity of gas $k$ & $0.5 \mathrm{~W} /(\mathrm{m} \cdot \mathrm{K})$
\end{tabular}




$\begin{array}{llll}\text { Density of preform } \rho_{\mathrm{p}} & 1760 \mathrm{~kg} / \mathrm{m} 3 & \text { Thermal conductivity of preform } k_{\mathrm{p}} & 140 \mathrm{~W} /(\mathrm{m} \cdot \mathrm{K}) \\ \text { Activation energy } \mathrm{Er} & 2.96 \times 10^{5} \mathrm{~J} / \mathrm{mol} & \text { Preexponential factor } k_{0} & 3.89 \times 10^{9} \mathrm{~m} / \mathrm{s}\end{array}$

\section{Results and discussions}

\subsection{The effect of inlet MTS concentration}
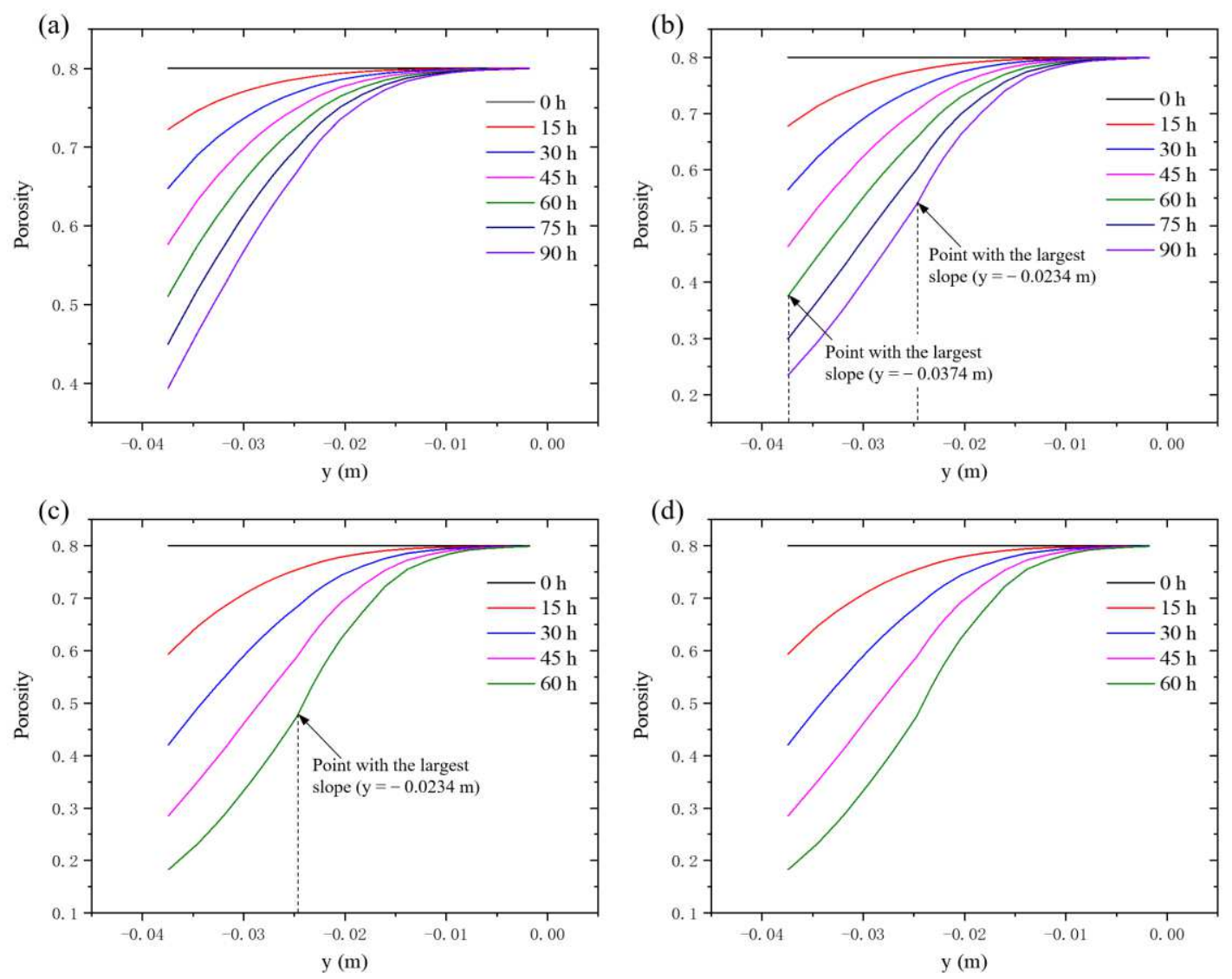

Fig. 2 Porosity variations over time along line $l_{\mathrm{v}}$ under different inlet MTS concentration. (a) $0.086 \mathrm{~mol} / \mathrm{m}^{3}$; (b) $0.136 \mathrm{~mol} / \mathrm{m}^{3}$; (c) $0.186 \mathrm{~mol} / \mathrm{m}^{3}$; (d) $0.236 \mathrm{~mol} / \mathrm{m}^{3} . T_{\text {top }}=900 \mathrm{~K}, T_{\text {bottom }}=1150 \mathrm{~K}$, inlet velocity $0.0127 \mathrm{~m} / \mathrm{s}, \mathrm{A}$ in C out.

The effect of inlet MTS concentration on the preform porosity was first explored. The gas mixture flows from A to C (Fig. 1), inlet velocity $0.0127 \mathrm{~m} / \mathrm{s}, T_{\text {top }} 900 \mathrm{~K}$ and $T_{\text {bottom }} 1150 \mathrm{~K}$. Fig. 2 shows the porosity variations over time along the line $l_{\mathrm{v}}$ under different inlet MTS concentration. Generally, the porosity distribution of the four cases in Fig. 2 is similar, that is, the porosity drops rapidly at the bottom of the line $l_{\mathrm{v}}$ while remains unchanged at the top side; given that the fresh precursors flow from the 
top to the bottom of the preform, it can be deduced that the temperature $T_{\text {top }} 900 \mathrm{~K}$ is too low for the chemical reaction. One can find that the deposition rate increases as the increase of inlet MTS concentration. For instance, it takes $75 \mathrm{~h}$ for porosity at the point $\mathrm{M}$ to decrease to 0.3 in the case of inlet MTS concentration $0.136 \mathrm{~mol} / \mathrm{m}^{3}$ (Fig. 2b), while it just needs $45 \mathrm{~h}$ in the case of inlet MTS concentration $0.236 \mathrm{~mol} / \mathrm{m}^{3}$ (Fig. 2d). One can also notice that the gap between two adjacent lines gradually decreases over time in each case (Fig. 2), which could be caused by a continuous shrink of MTS concentration over time (Fig. 3a). Besides, under a certain inlet MTS concentration, the position of the largest slope moves upward over time, for instance, in Fig. $2 b$ the largest slope of the curve $t=60 \mathrm{~h}$ is at $\mathrm{y}=-0.0374 \mathrm{~m}$, while on the curve $t=90 \mathrm{~h}$ it is at $\mathrm{y}=-0.0234 \mathrm{~m}$. Likewise, the largest slope position moves upward as the increase of inlet MTS concentration, for example, the largest slope of the curve $t=60$ $\mathrm{h}$ in the case of inlet MTS concentration $0.136 \mathrm{~mol} / \mathrm{m}^{3}$ is at $\mathrm{y}=-0.0374 \mathrm{~m}$ (Fig. 2b), while on the curve $t=60 \mathrm{~h}$ in the case of inlet MTS concentration $0.186 \mathrm{~mol} / \mathrm{m}^{3}$ it is at $y=-0.0234 \mathrm{~m}$ (Fig. 2c). These may mainly attribute to the deposition, that is, the increase of infiltration time or inlet MTS concentration results in more deposition, which will raise the thermal conductivity and induce more heat transferring upward from the bottom high-temperature zone (Fig. 3b). Given that the precursor flows downwards, the upward heat gives rise to the moving upward of the largest slope position. 

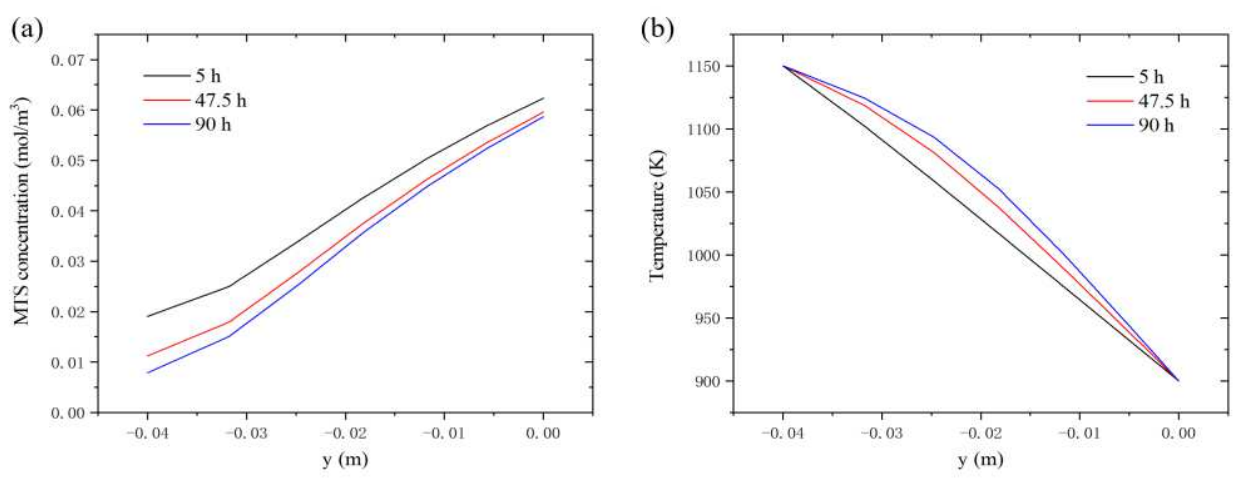

Fig. 3 MTS concentration (a) and temperature (b) variations over time along line $l_{\mathrm{v}}$ in the case of inlet MTS concentration $0.086 \mathrm{~mol} / \mathrm{m}^{3}, T_{\text {top }}=900 \mathrm{~K}, T_{\text {bottom }}=1150 \mathrm{~K}$, inlet velocity $0.0127 \mathrm{~m} / \mathrm{s}, \mathrm{A}$ in C out.

\subsection{The effect of inlet velocity}

Fig. 4 shows the porosity and velocity at point M under different inlet velocity at $t$ $=50 \mathrm{~h}$. It presents a simple lineal relationship, that is, as the inlet velocity increases, the velocity at the point M synchronously increases (the red line in Fig. 4), and the porosity lineally decreases (the black line in Fig. 4). When inlet velocity is $0.0027 \mathrm{~m} / \mathrm{s}$, the velocity at point $\mathrm{M}$ is just $0.0016 \mathrm{~m} / \mathrm{s}$, a decay about 40 percentage, and after an infiltration of $50 \mathrm{~h}$ the porosity is still as high as 0.463 . On the other hand, as the inlet velocity increase by $0.005 \mathrm{~m} / \mathrm{s}$ (a corresponding total gas flow of $2.34 \mathrm{l} / \mathrm{min}$ ), the porosity just decreases by about 0.06 , which is far from economical.

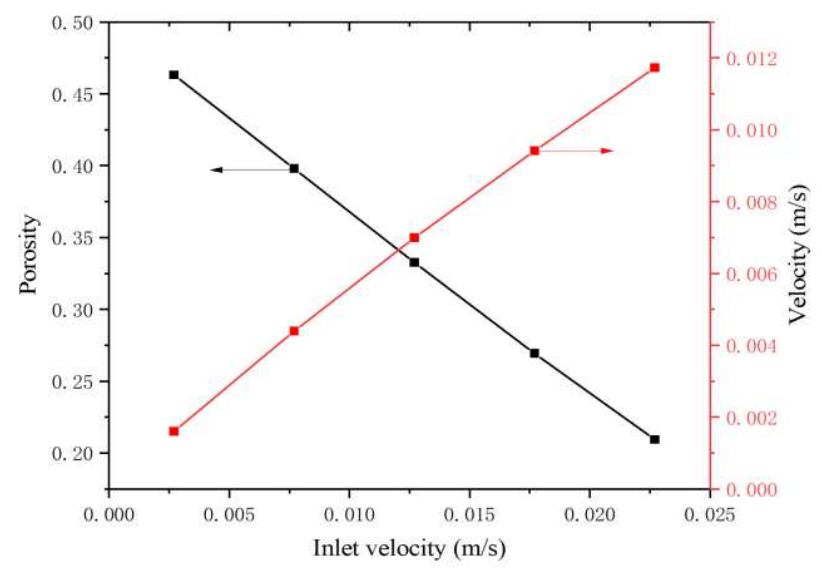

Fig. 4 Porosity and velocity at the point M under different inlet velocity. Inlet MTS concentration $0.186 \mathrm{~mol} / \mathrm{m}^{3}$, $T_{\text {top }}=900 \mathrm{~K}, T_{\text {bottom }}=1150 \mathrm{~K}, \mathrm{~A}$ in C out, infiltration time $t=50 \mathrm{~h}$. 
Furtherly, we checked the MTS concentration and temperature distribution on the line $l_{\mathrm{v}}$ to find more information about the effect of inlet velocity. As shown in Fig. 5a, the increase of inlet velocity can improve the MTS concentration on the whole line $l_{\mathrm{v}}$, but more obvious at the upside (top portion of the preform). Inlet velocity also has positive effect on the temperature distribution, but in a tiny degree (Fig. 5b). To sum up, the increase of inlet velocity will accelerate the deposition by increasing the concentration of MTS in the preform, but it is neither effective nor economic due to the large $\mathrm{H}_{2}$ /MTS molar ratio. Hence, a moderate inlet velocity will be better for guaranteeing a forced-flow and an economic densification.
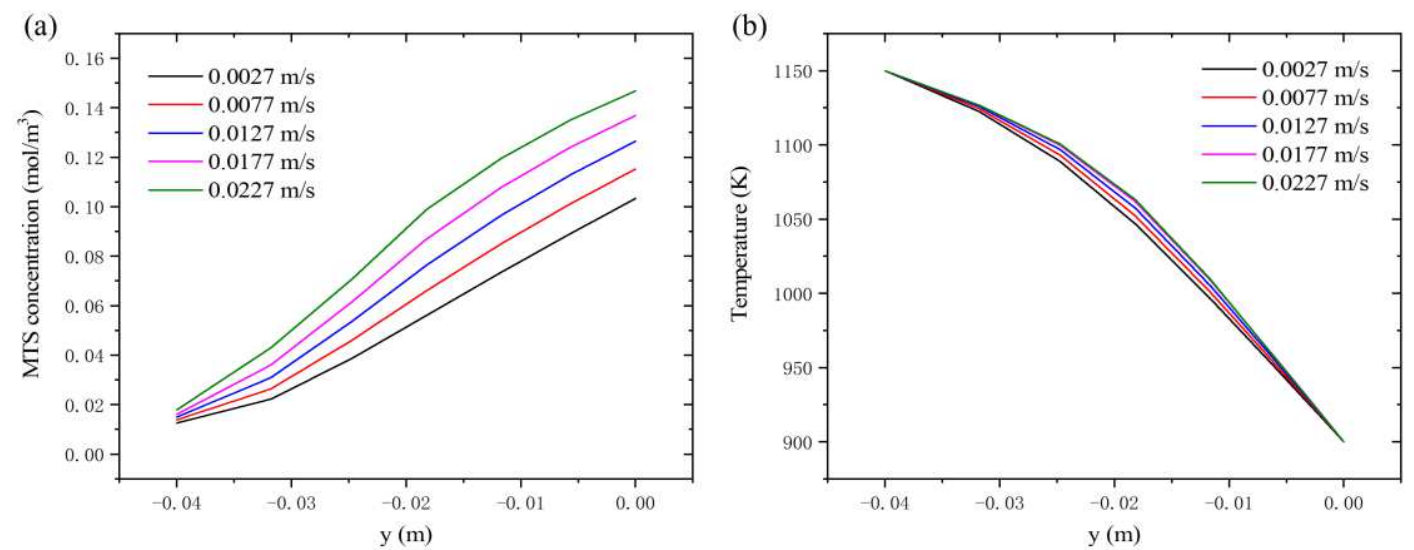

Fig. 5 MTS concentration and temperature distribution along line $l_{\mathrm{v}}$ under different inlet velocity. Inlet MTS concentration $0.186 \mathrm{~mol} / \mathrm{m}^{3}, T_{\text {top }}=900 \mathrm{~K}, T_{\text {bottom }}=1150 \mathrm{~K}$, A in C out, infiltration time $t=50 \mathrm{~h}$.

\subsection{The effect of temperature}

The effect of temperature was also investigated. Under conditions of $\mathrm{A}$ in $\mathrm{C}$ out, inlet MTS concentration $0.186 \mathrm{~mol} / \mathrm{m}^{3}$ and inlet velocity $0.0127 \mathrm{~m} / \mathrm{s}$, a number of cases with different top-bottom temperature pairs were simulated. Fig. 6 presents four typical cases: in the case one $T_{\text {top }}=900 \mathrm{~K}$ and $T_{\text {bottom }}=1150 \mathrm{~K}$, the bottom preform was firstly densified (Fig. 6a) due to the excessively low top temperature; things are changed in the case of $T_{\text {top }}=1100 \mathrm{~K}, T_{\text {bottom }}=1200 \mathrm{~K}$. The bottom temperature is still higher than the top temperature, but the top temperature $1100 \mathrm{~K}$ is high enough for 
reaction, thus densification mainly occurs at the top portion (Fig. 6b) where the precursor concentration is higher; when $T_{\text {bottom }}$ remains at $1200 \mathrm{~K}$, but the $T_{\text {top }}$ is lowered to $1050 \mathrm{~K}$. The porosity distribution over the whole preform notably changes once again. As shown in Fig. 6c, the most distinguished porosity decrease occurs at the middle portion; when the preform is kept iso-thermal, $1000 \mathrm{~K}$, the densification over the whole preform is quite uniform, but the deposition is very slow (Fig. 6d).
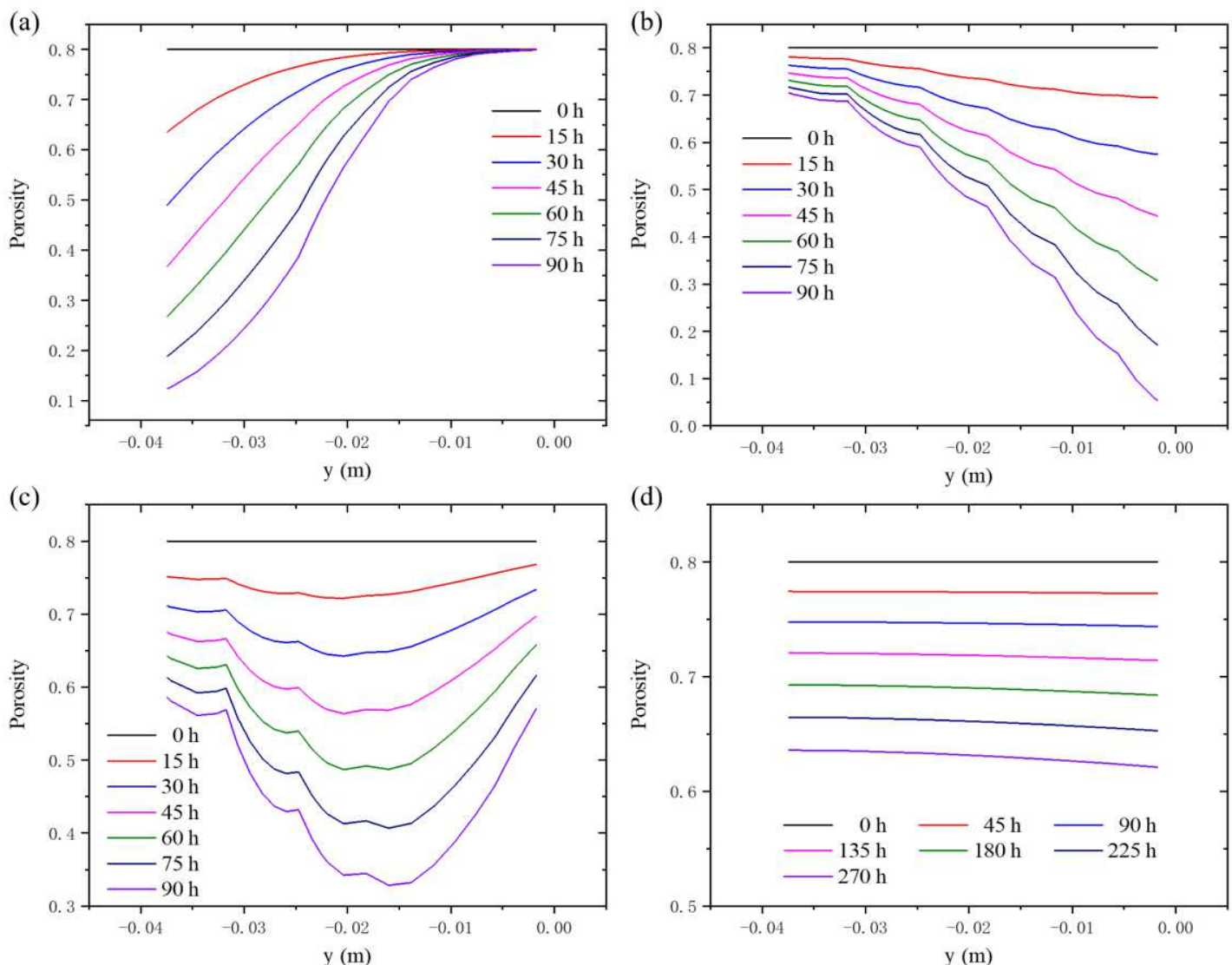

Fig. 6 Porosity variations over time along line $l_{\mathrm{v}}$ under different temperature pairs. (a) $T_{\text {top }}=900 \mathrm{~K}, T_{\text {bottom }}=1150$ $\mathrm{K}$; (b) $T_{\text {top }}=1100 \mathrm{~K}, T_{\text {bottom }}=1200 \mathrm{~K}$; (c) $T_{\text {top }}=1050 \mathrm{~K}, T_{\text {bottom }}=1200 \mathrm{~K} ;\left(\right.$ d) $T_{\text {top }}=1000 \mathrm{~K}, T_{\text {bottom }}=1000 \mathrm{~K}$ $\mathrm{mol} / \mathrm{m}^{3}$. Inlet MTS concentration $0.0186 \mathrm{~mol} / \mathrm{m}^{3}$, inlet velocity $0.0127 \mathrm{~m} / \mathrm{s}, \mathrm{A}$ in C out.

In the cases of Fig. $6 b$ and Fig. 6c, the only difference is the top temperature, i.e., $1100 \mathrm{~K}$ in the case $\mathrm{b}$ and $1050 \mathrm{~K}$ in the case $\mathrm{c}$, but this small temperature difference causes quite different porosity distribution. Initially, as shown by Fig.7, the porosity difference of the two cases is quite small in magnitude (about 0.003 ) at $t=1 \mathrm{~h}$. The distribution trend, however, is already quite evident. That is, in the case b, porosity at 
the top portion of the preform is smaller due to the higher top temperature (more intense reaction); while reaction at the top portion in the case $\mathrm{c}$ is less intense, thus more precursors reaching to the middle-lower portion where the temperature is higher, as a result, the middle-lower portion of the preform has the lowest porosity (Fig. 7).

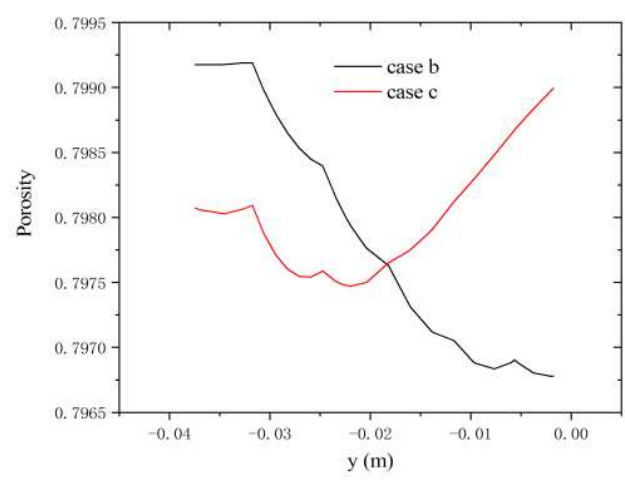

Fig. 7 Porosity distribution in the case $\mathrm{b}$ and $\mathrm{c}$ at $t=1 \mathrm{~h}$.

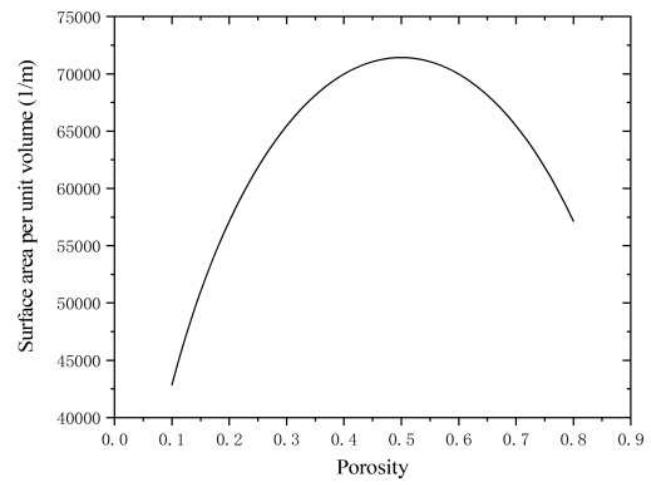

Fig. 8 Relationship of surface area with porosity.

The initial porosity distribution will strongly affect the successive distribution of some parameters, such as surface area per unit volume, MTS concentration and temperature. According to the relationship between surface area per unit volume and porosity [19], the decrease of porosity will cause the surface area to increase first and then decrease (Fig. 8). Therefore, the porosity distribution trend in Fig. 7 will lead to a different surface area distribution in the two cases, i.e., larger surface area at the top portion in the case $\mathrm{b}$ while larger surface area at the middle portion in the case $\mathrm{c}$, as shown in Fig. 9a and Fig. 9d. Likewise, the MTS concentration also closely relates to the porosity distribution: in the case $b$, the porosity at the top portion of the preform drops rapidly, which means a gradually plugging at the top portion and results in more precursors staying at the top portion (Fig. 9b); while lower top temperature and coarser top preform in the case $\mathrm{c}$ induce a higher MTS concentration through the whole preform (Fig. 9e). In terms of the temperature, as explained in section 3.1, the porosity relates to the thermal conductivity and furtherly affects the temperature distribution. In the case $b$, the thermal conductivity at the top portion is higher, 
corresponding to the smaller temperature gradient at the top portion (Fig. 9c), while in the case $\mathrm{c}$, the smaller temperature gradient occurs near the middle portion (Fig. 9f). As we should remember, the temporal distribution of porosity is proportional to the reaction rate $R_{1}$, more specifically, it is proportional to the surface area, MTS concentration and temperature $\left(R_{1}=k_{\mathrm{s}} c_{1} S_{\mathrm{V}}\right)$. That is to say, the initial parameters bring about an initial porosity distribution trend, this initial porosity distribution furtherly induces a corresponding parameter change, which in turn, will enhance the porosity distribution trend.
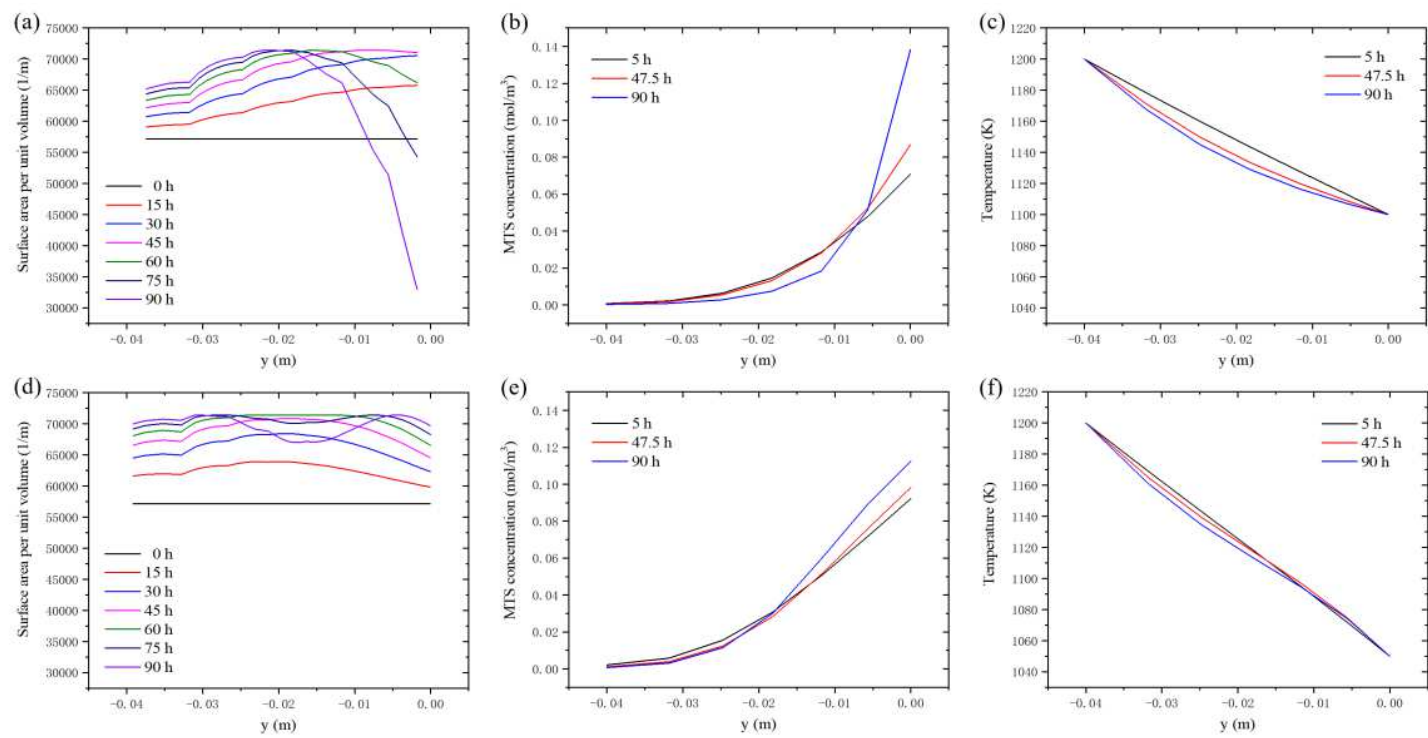

Fig. 9 Surface area per unit volume, MTS concentration and temperature variations over time along the line $l_{\mathrm{v}}$ corresponding to the case $b(a-c)$ and the case $c(d-f)$.

\subsection{The two-step densification scheme}

According to Fig. 6a and Fig. 6b, a two-step densification scheme which has the possibility to simply densify the preform was proposed: The gas mixture first flows from A to C (Fig. 10a) to densify a half of the preform, and then the gas flows form C to B (Fig. 10b) to finish the densification of the remaining half. 
(a)

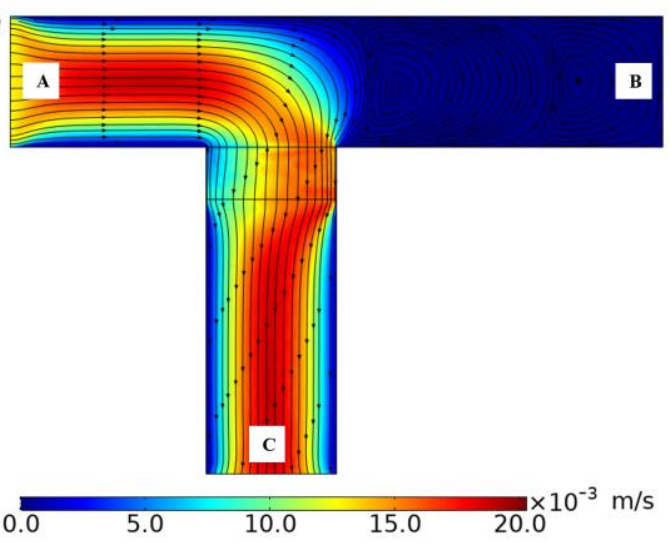

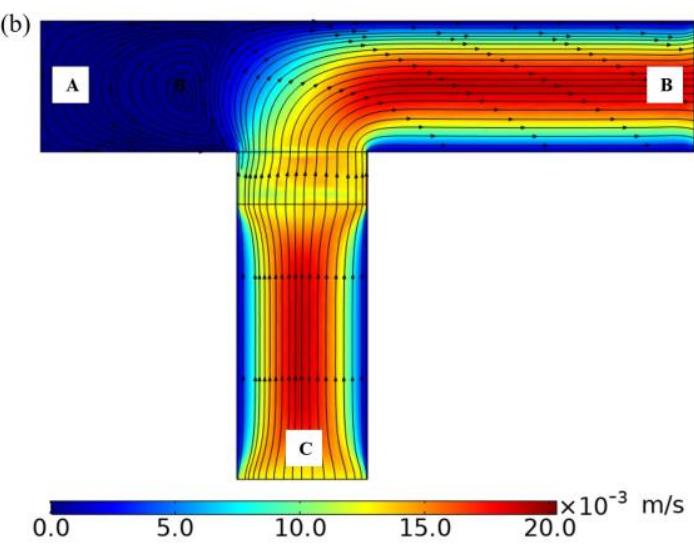

Fig. 10 Streamlines distribution at the last hour of each step in a simple two-step densification scheme. The detailed parameters are listed in table 2 . The vectors give the direction, and the color gives the magnitude in $\mathrm{m} / \mathrm{s}$.

Cases with different parameters were tried, and table 2 lists a viable one. In this case, porosity at the upper portion quickly drops due to the suitable temperature and fresh precursors, and the other portion of the preform is also densified to some degree with the aid of high bottom temperature $1200 \mathrm{~K}$ (Fig. 11a). In the next step, the top and bottom temperature arrangement is reversed. The gas mixture flows from $\mathrm{C}$ to $\mathrm{B}$, and the lower portion of the preform is densified (Fig. 11b).

Table 2 List of parameters used in the two-step densification scheme

\begin{tabular}{|c|c|c|c|c|c|c|}
\hline \multirow{2}{*}{ Steps } & \multicolumn{2}{|c|}{ Temperature (K) } & \multirow{2}{*}{$\begin{array}{l}\text { Inlet MTS concentration } \\
\qquad\left(\mathrm{mol} / \mathrm{m}^{3}\right)\end{array}$} & \multirow{2}{*}{$\begin{array}{l}\text { Inlet velocity } \\
\qquad(\mathrm{m} / \mathrm{s})\end{array}$} & \multirow{2}{*}{$\begin{array}{l}\text { Inlet and } \\
\text { outlet }\end{array}$} & \multirow{2}{*}{$\begin{array}{l}\text { Infiltration } \\
\text { time (h) }\end{array}$} \\
\hline & $T_{\text {top }}$ & $T_{\text {bottom }}$ & & & & \\
\hline step I & 1100 & 1200 & 0.186 & 0.0127 & $\mathrm{~A}$ in $\mathrm{C}$ out & 45 \\
\hline step II & 1200 & 1100 & 0.186 & 0.0127 & $\mathrm{C}$ in $\mathrm{B}$ out & 45 \\
\hline
\end{tabular}
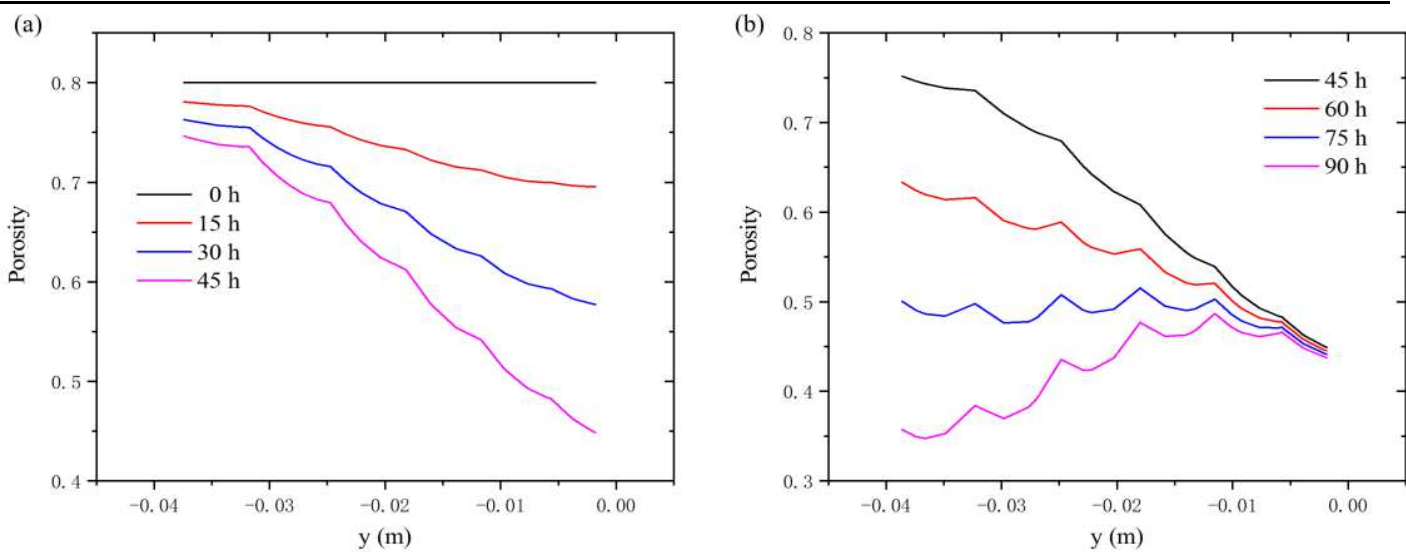

Fig. 11 Porosity variations over time along line $l_{\mathrm{v}}$ in a simple two-step densification scheme. (a) - (b) Step I - Step II. The detailed parameters are listed in table 2. 
As can be noticed, the infiltration time in the two steps are short and the final porosity is rather high (Fig. 11b). Actually, cases with longer infiltration time were tried but they all failed. The reason lies in the high reaction rate at a specific region. When the gas flows from A to $\mathrm{C}$, the upper left corner of the preform has the thinnest concentration boundary layer, i.e., the highest concentration. Moreover, the temperature there $(1100 \mathrm{~K})$ is suitable for the pyrolysis, thus the overlay of high concentration and temperature giving rise to an extremely low porosity zone at the upper left corner (Fig. 12a). The porosity of somewhere at the upper left corner decreases to zero when the total infiltration time exceeds 90 hours. As a result, the simulation cannot go on even if the maximum porosity over the entire preform is still as high as 0.5 (Fig. 12b).
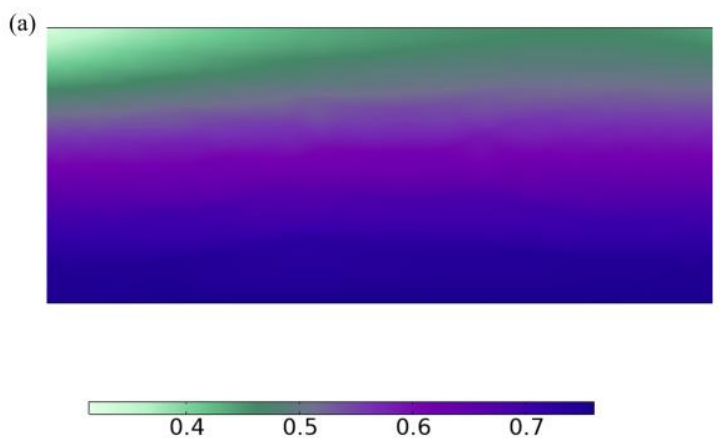
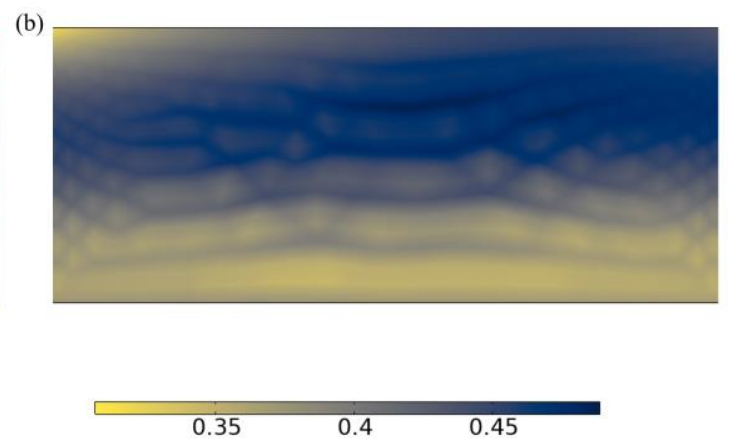

Fig. 12 Contour of porosity variations over the whole preform at the last hour of each step in a simple two-step densification scheme. (a) - (b) Step I - Step II. The detailed parameters are listed in table 2. Porosity in the two steps differs a lot, for the convenience of viewing, different bars and color systems were used in the porosity contours.

\subsection{The three-step densification scheme}

To avoid the overlay of high concentration and high temperature, a three-step densification scheme was proposed: In the first step the gas flows from A to C (Fig. 13a), and deposition mainly occurs at the bottom portion where temperature is high; in the middle step the gas still flows from A to C (Fig. 13b), but the top and bottom temperature is adjusted so that the middle portion can be densified; due to the 
plugging of most of the preform, if we still pump all the gas out from the outlet $\mathrm{C}$, the huge stress may cause preform cracking [17], thus in the final step the gas mixture flows from A to B (Fig. 13c), and precursors diffuse into the top portion to densify the remaining coarse top preform.
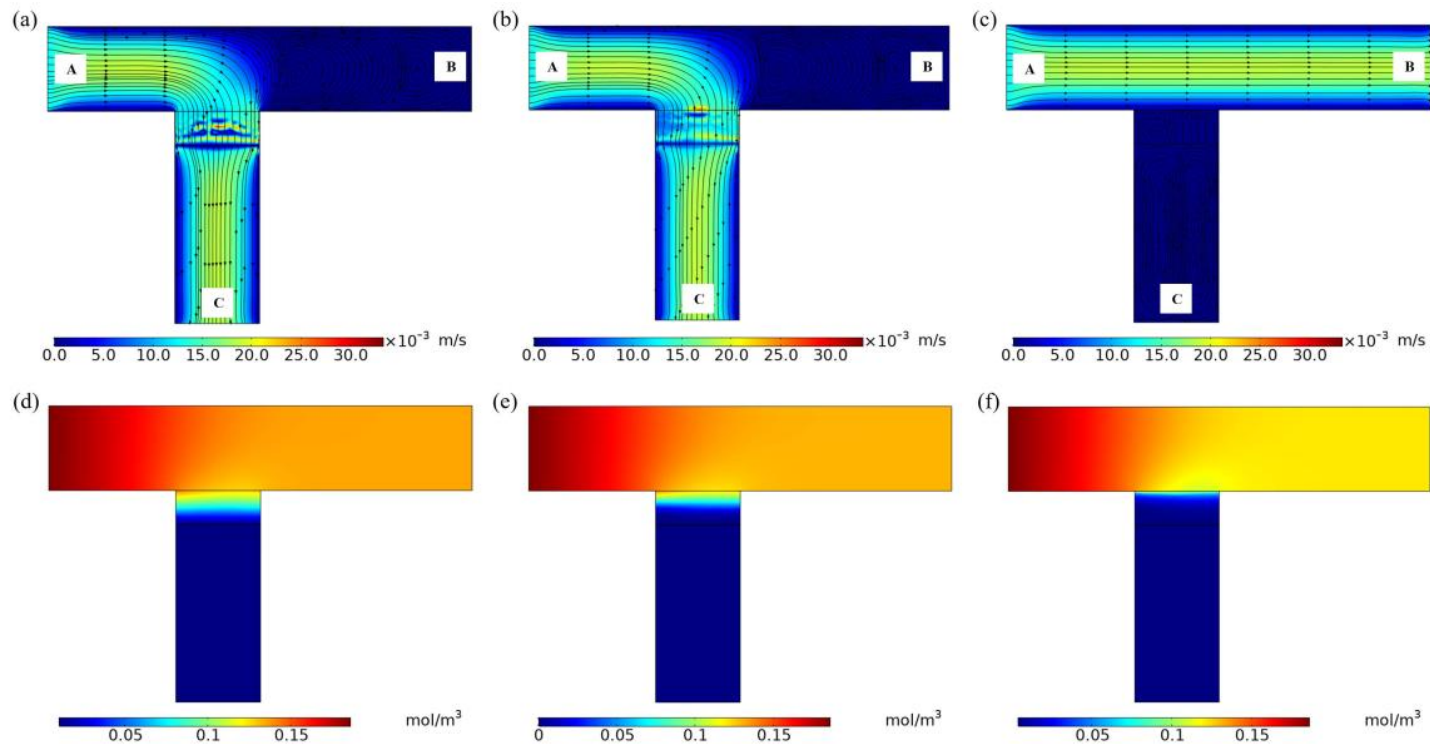

Fig. 13 Streamlines (a-c) and MTS concentration (d-f) distribution at the last hour of each step in the three-step densification scheme. The detailed parameters are listed in table 3. The vectors give the direction, and the color gives the magnitude in $\mathrm{m} / \mathrm{s}$ or $\mathrm{mol} / \mathrm{m}^{3}$.

Table 3 List of parameters used in a three-step densification scheme

\begin{tabular}{|c|c|c|c|c|c|c|}
\hline \multirow{2}{*}{ Steps } & \multicolumn{2}{|c|}{ Temperature $(\mathrm{K})$} & \multirow{2}{*}{$\begin{array}{l}\text { Inlet MTS concentration } \\
\qquad\left(\mathrm{mol} / \mathrm{m}^{3}\right)\end{array}$} & \multirow{2}{*}{$\begin{array}{c}\text { Inlet velocity } \\
\qquad(\mathrm{m} / \mathrm{s})\end{array}$} & \multirow{2}{*}{$\begin{array}{c}\text { Inlet and } \\
\text { outlet }\end{array}$} & \multirow{2}{*}{$\begin{array}{l}\text { Infiltration } \\
\text { time (h) }\end{array}$} \\
\hline & $T_{\text {top }}$ & $T_{\text {bottom }}$ & & & & \\
\hline step I & 900 & 1150 & 0.186 & 0.0127 & $\mathrm{~A}$ in $\mathrm{C}$ out & 85 \\
\hline step II & 1050 & 1200 & 0.186 & 0.0127 & $\mathrm{~A}$ in $\mathrm{C}$ out & 80 \\
\hline step III & 1125 & 1050 & 0.186 & 0.0127 & $A$ in $B$ out & 35 \\
\hline
\end{tabular}

Cases with different parameters were simulated. By comparing the final porosity and total infiltration time, table 3 lists a relatively good one. In the step I, due to the low top temperature $900 \mathrm{~K}$, the precursor can reach far deep to the lower middle preform (Fig. 13d), and porosity near the bottom preform decreases significantly as expected (Fig. 14a). In the next step, with higher top and bottom temperature, the reaction zone moves upward, the precursor is almost depleted at the middle portion 
(Fig. 13e), and the middle portion of the preform is densified (Fig. 14b). In these two steps, as the lower part of the preform first gets plugged, the porosity gradient induces an oscillatory flow in the preform (Fig. 13a-b). In the final step, the precursor diffuses into the top preform (Fig. 13f) and the remaining coarse top preform is also densified (Fig. 14c)
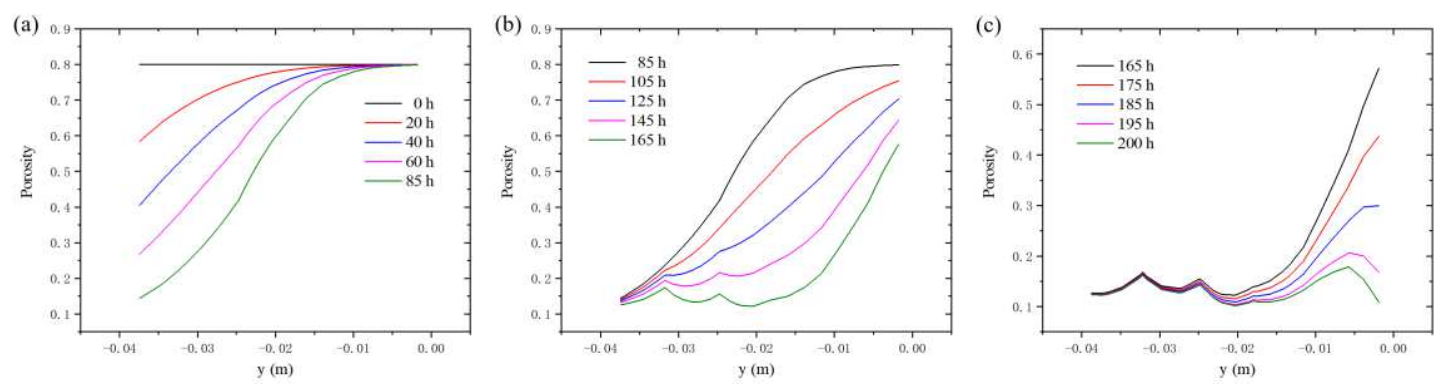

Fig. 14 Porosity variations over time along line $l_{\mathrm{v}}$ in a three-step densification scheme. (a) - (c) step I - step III. The detailed parameters are listed in table 3.

The three-step densification scheme significantly lowers the porosity of the whole preform, but the uniformity still needs to be improved. In the first two steps the deposition zone gradually moves from the bottom to the top. There is an obvious stratification and porosity in each layer is quite uniform, as shown by Fig. 15a and Fig. 15b. In the step III, however, the unwanted impermeable skin arises at the upper left corner of the preform while porosity under the right surface is still as high as 0.19 (Fig. 15c). Likewise, the two blue high-porosity strips near the bottom preform are also very eye-catching.
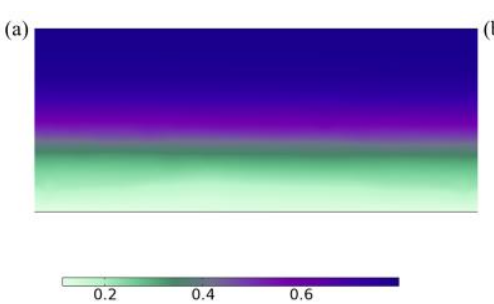
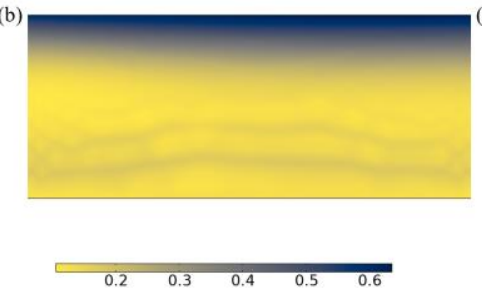
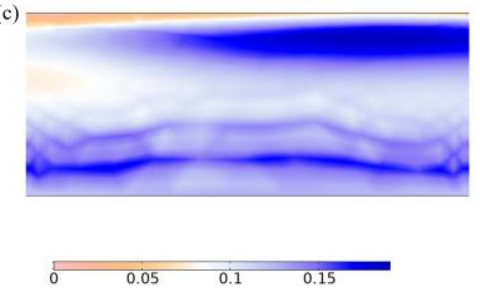

Fig. 15 Contour of porosity variations over the whole preform at the last hour of each step in the three-step densification scheme. (a) - (c) Step I - Step III. The detailed parameters are listed in table 3.

Three measures were taken to improve the three-step densification scheme. 1. In the step I and II, extend the infiltration time to eliminate the high-porosity strips near 
the bottom preform. 2. In the step III, pump part of gases out from the outlet $\mathrm{C}$ to increase the MTS concentration in the preform. 3. In the step III, uniform the deposition (reaction rate) at the top portion by applying a horizontal linearly increasing temperature on the top edge of the preform to offset the effect of horizontally decreasing concentration. The measure of horizontal temperature gradient fixes the problem of the rapid sealing of the upper left corner, so the simulation can run longer in the step III. Additionally, the gas pumping from the outlet $\mathrm{C}$ obviously increases the concentration near the top portion (Fig.16). The detail parameters of improved three-step densification scheme are given in table 4. As can be seen from Fig. 17, the densification situation is significantly improved, i.e., the porosity over whole preform is not only lower but also more uniform (Fig. 17b).
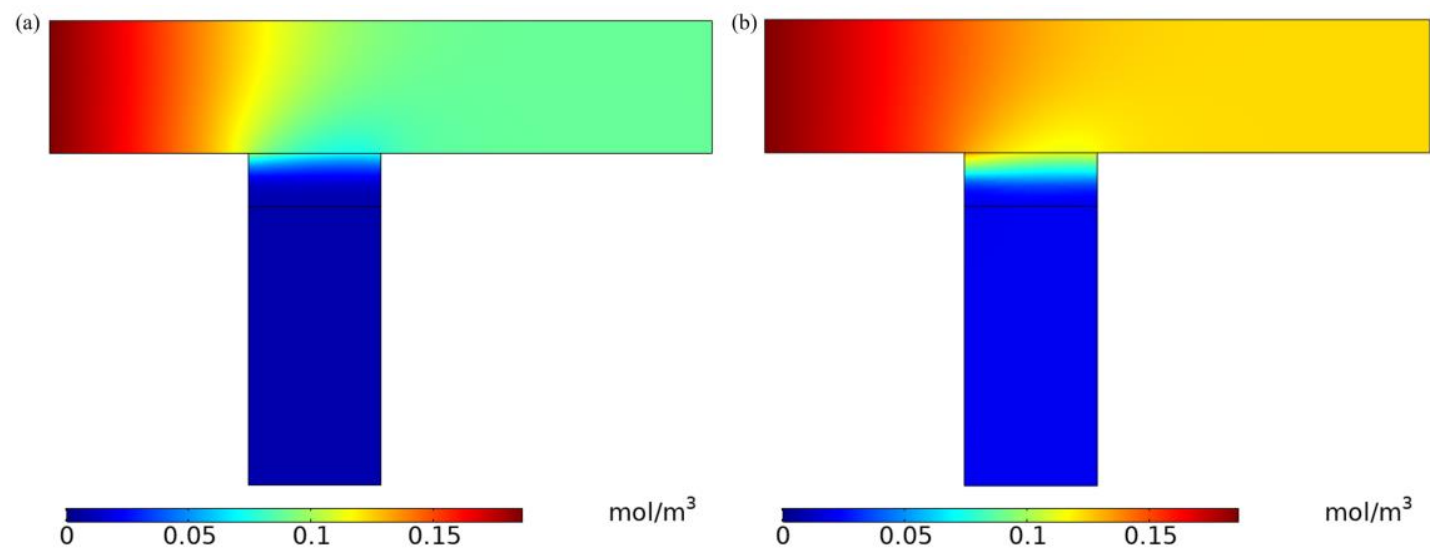

Fig. 16 Contour of MTS concentration distribution at $t=1 \mathrm{~h}$ under different outlet condition. (a) A in B out; (b) A in, B and C out.

Table 4 List of parameters used in the improved three-step densification scheme

\begin{tabular}{|c|c|c|c|c|c|c|}
\hline \multirow{2}{*}{ Steps } & \multicolumn{2}{|c|}{ Temperature (K) } & \multirow{2}{*}{$\begin{array}{c}\text { Inlet MTS } \\
\text { concentration }\left(\mathrm{mol} / \mathrm{m}^{3}\right)\end{array}$} & \multirow{2}{*}{$\begin{array}{l}\text { Inlet velocity } \\
\qquad(\mathrm{m} / \mathrm{s})\end{array}$} & \multirow{2}{*}{$\begin{array}{c}\text { Inlet and } \\
\text { outlet }\end{array}$} & \multirow{2}{*}{$\begin{array}{l}\text { Infiltration } \\
\text { time }(\mathrm{h})\end{array}$} \\
\hline & $T_{\text {top }}$ & $T_{\text {bottom }}$ & & & & \\
\hline step I & 900 & 1150 & 0.186 & 0.0127 & $A$ in, $C$ out & 90 \\
\hline step II & 1050 & 1200 & 0.186 & 0.0127 & $A$ in, $C$ out & 90 \\
\hline step III & $\begin{array}{l}80 x+1075 \\
0 \leqslant x \leqslant 0.1\end{array}$ & 1050 & 0.186 & 0.0127 & A in, B C out & 120 \\
\hline
\end{tabular}



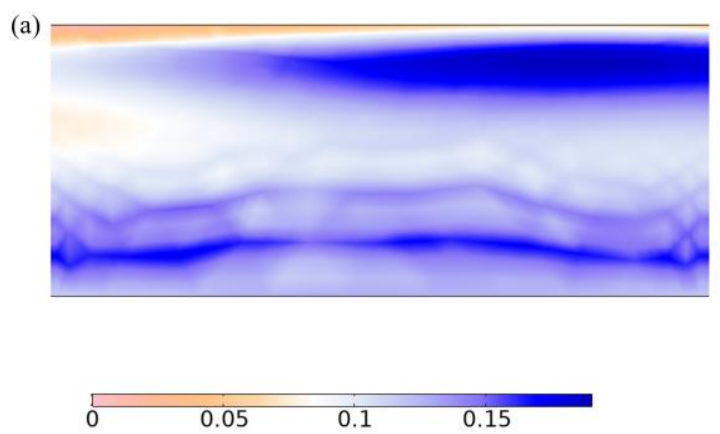
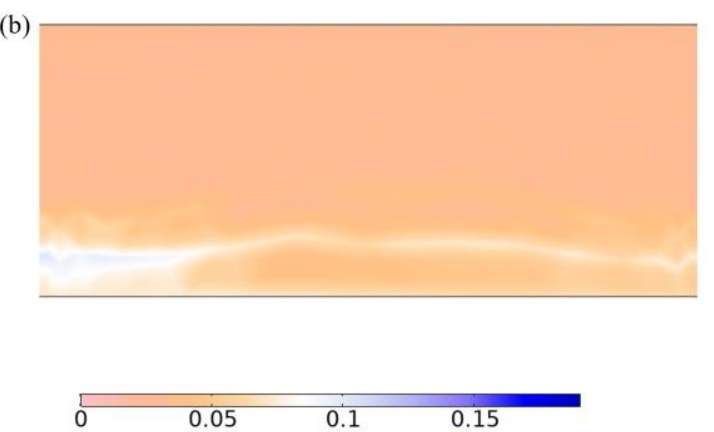

Fig. 17 Contour of porosity distribution (a) before and (b) after some improvements being taken in the three-step densification scheme.

\section{Conclusions}

In the present paper a two-channel temperature-control infiltration reactor aiming at fabricating thicker and more uniform composites was designed. The effects of concentration, velocity and temperature on the porosity distribution were first analyzed, based on which different densification schemes were proposed and compared. By adopting improving measures, an optimal densification scheme was given.

(1) The densification rate can be accelerated by increasing the inlet MTS concentration (MTS molar ratio) or inlet velocity (total gas flow), while the former is more effective. The deposition behavior is mainly determined by the top and bottom temperature, a small temperature difference can dramatically change the porosity distribution. Temperature, concentration and velocity determine the porosity evolution, the porosity evolution, in turn, also affects the distribution of these parameters.

(2) A three-step densification scheme based on the two-channel reactor is proposed: In the first step the gas flows through the preform whose top temperature is not suitable for reaction, and deposition mainly occurring at the high-temperature bottom portion; in the middle step the top and bottom temperature is adjusted to assure certain deposition occurring at the middle portion; in the final step, the two outlets (pump) 
are all open, and a linearly increasing temperature is applied to the top edge of the preform, whereby the coarse top portion is furtherly densified. This scheme avoids the unwanted sealing of preform by separating the high precursor concentration region from the high temperature region. Besides, in the step III a part of the gas is pumped out from the outlet C, and the main flow doesn't go through the dense preform, which not only assures the precursor supply in the preform but also protects the fiber preform from cracking due to the huge pumping pressure.

\section{Acknowledgements}

This work is supported by National Key R\&D Program of China (No. 2017YFC0803300), National Natural Science Foundation of China (Grant Nos. 7204100828, 91646201, U1633203), China Postdoctoral Science Foundation (No. 2019M660699), High-tech Discipline Construction Fundings for Universities in Beijing (Safety Science and Engineering) and Beijing Key Laboratory of City Integrated Emergency Response Science.

\section{References}

[1] Baldus P, Jansen M, Sporn D. Ceramic fibers for matrix composites in hig h-temperature engine applications. Science 1999, 285: 699-703.

[2] Krenkel W. Ceramic Matrix Composites: Fiber Reinforced Ceramics and their Applications. New York: John Wiley \& Sons, 2008.

[3] Besmann TM, Sheldon BW, Lowden RA, et al. Vapor-phase fabrication and properties of continuous-filament ceramic composites. Science 1991, 253: 1104-1109.

[4] Bickerdike R, Brown A, Hughes G, et al. The deposition of pyrolytic carbon in the pores of bonded and unbonded carbon powders. In Proceedings of the Fifth 
Conference on Carbon. McClure JW, Yafet Y, Eds. London: Pergamon Press, 1962: $575-582$.

[5] Shi QL, Xiao P. Effect of pyrolytic carbon content on microstructure and tribological properties of $\mathrm{C} / \mathrm{C}-\mathrm{SiC}$ brake composites fabricated by isothermal chemical vapor infiltration. Solid State Sci 2012, 14: 26-34.

[6] Reuge N, Vignoles GL. Modeling of isobaric-isothermal chemical vapor infiltration: effects of reactor control parameters on a densification. J Mater Process Tech 2005, 166: 15-29.

[7] Wei X, Cheng LF, Zhang LT, et al. A two-dimensional model for densification behaviour of $\mathrm{C} / \mathrm{SiC}$ composites in isothermal chemical vapour infiltration. Model Simul Mater Sci 2006, 14: 891-904.

[8] Hua YF, Zhang LT, Cheng LF, et al. A two-process model for study of the effect of fiber preform structure on isothermal chemical vapor infiltration of silicon carbide matrix composites. Comp Mater Sci 2009, 46: 133-141.

[9] Naslain R, Langlais F. Fundamental and practical aspects of the chemical vapor infiltration of porous substrates. High Temp Sci 1989, 27: 221-235.

[10]Caputo AJ, Lackey WJ. Fabrication of fiber-reinforced ceramic composites by chemical vapor infiltration. In Proceedings of the 8th Annual Conference on Composites and Advanced Ceramic Materials. Ohio: The American Ceramic Society, 1984: 654-667.

[11]Besmann TM, Stinton DP, Lowden RA. Chemical vapor deposition techniques. MRS Bull 1988. 13: 45-51.

[12]Besmann TM, Lowden RA, Stinton DP, et al. A method for rapid chemical vapor infiltration of ceramic composites. Le Journal de Physique Colloques 1989, 50: C5-229-C5-239. 
[13] Vaidyaraman S, Lackey WJ, Freeman GB, et al. Fabrication of carbon-carbon composites by forced flow-thermal gradient chemical vapor infiltration. J Mater Res 1995, 10: 1469-1477.

[14] Vaidyaraman S, Lackey WJ, Agrawal PK, et al. Forced flow-thermal gradient chemical vapor infiltration (FCVI) for fabrication of carbon/carbon. Carbon 1995, 33: $1211-1215$.

[15]Besmann TM, McLaughlin JC, Lin HT. Fabrication of ceramic composites: forced CVI. J. Nucl. Mater 1995, 219: 31-35.

[16]Probst KJ, Besmann TM, Stinton DP, et al. Recent advances in forced-flow, thermal-gradient CVI for refractory composites. Surf Coat Technol 1999. 120: 250-258.

[17]Morscher GN, Singh M, Kiser JD, et al. Modeling stress-dependent matrix cracking and stress-strain behavior in $2 \mathrm{D}$ woven $\mathrm{SiC}$ fiber reinforced CVI SiC composites. Compos Sci Technol 2007, 67: 1009-1017.

[18]Tang ZH, Qu DN, Xiong J, et al. Effects of infiltration conditions on the densification behavior of carbon/carbon composites prepared by a directional-flow thermal gradient CVI process. Carbon 2003, 41: 2703-2710.

[19] Vaidyaraman S, Lackey WJ, Agrawal PK, et al. 1-D model for forced flow-thermal gradient chemical vapor infiltration process for carbon/carbon composites. Carbon 1996, 34: 1123-1133.

[20]Lewis JS, Lackey WJ, Vaidyaraman S. Model for prediction of matrix microstructure for carbon/carbon composites prepared by forced flow-thermal gradient CVI. Carbon 1997, 35: 103-112.

[21] Ofori JY, Sotirchos SV. Investigation of the potential of forced-flow chemical vapor infiltration. J Electrochem Soc 1997, 144: 274-289. 
[22]Papasouliotis GD, Sotirchos SV. Stead-state multiplicity phenomena in the deposition of silicon carbide. J Electrochem Soc 1998, 145: 3908-3919.

[23]Comsol Multiphysics. Chemical reaction engineering module user's guide. 2019, $123-133$.

[24] Albright LF. Albright's chemical engineering handbook. Boca Raton: CRC Press, 2008.

[25]Comsol Multiphysics. Subsurface flow module user's guide. 2019, 168-170.

[26]Comsol Multiphysics. Heat transfer module user's guide. 2019, 171-175.

[27] Xu HJ, Xing ZB, Wang FQ, et al. Review on heat conduction, heat convection, thermal radiation and phase change heat transfer of nanofluids in porous media: Fundamentals and applications. Chem Eng Sci 2019, 195: 462-483.

[28] Wang FQ, Tan JY, Ma LX, et al. Thermal performance analysis of porous medium solar receiver with quartz window to minimize heat flux gradient. Sol Energy 2014, 108: 348-359. 
Figures

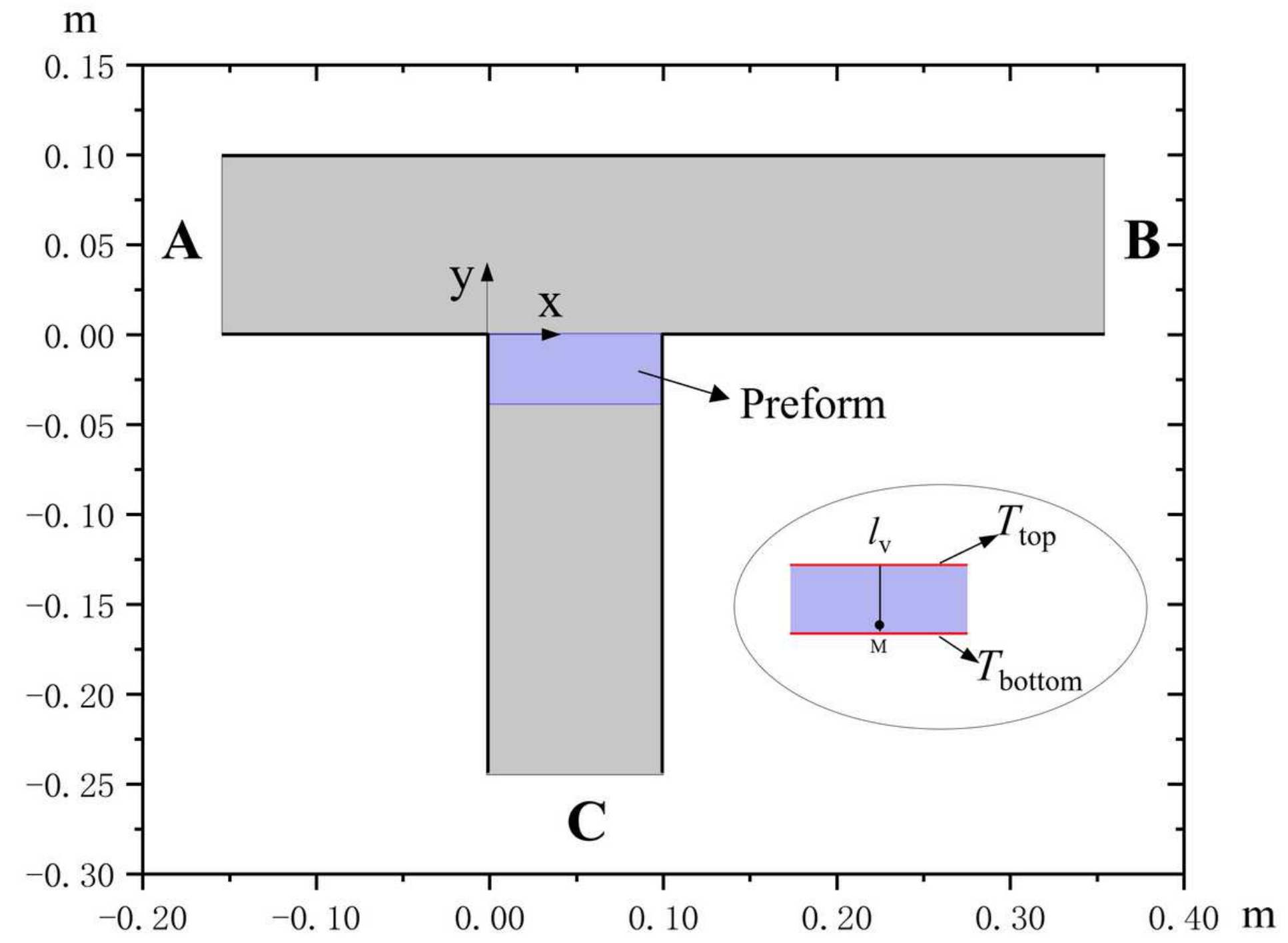

Figure 1

Schematic of physical model. For the convenience of results display, the vertical midline of preform is marked as Iv, the coordinate origin is set at the top-left end point of the preform and the point $(0.05$, -0.0374 ) is marked as $M$, the temperature at the top and bottom edges of the preform are marked as Ttop and Tbottom, respectively. 

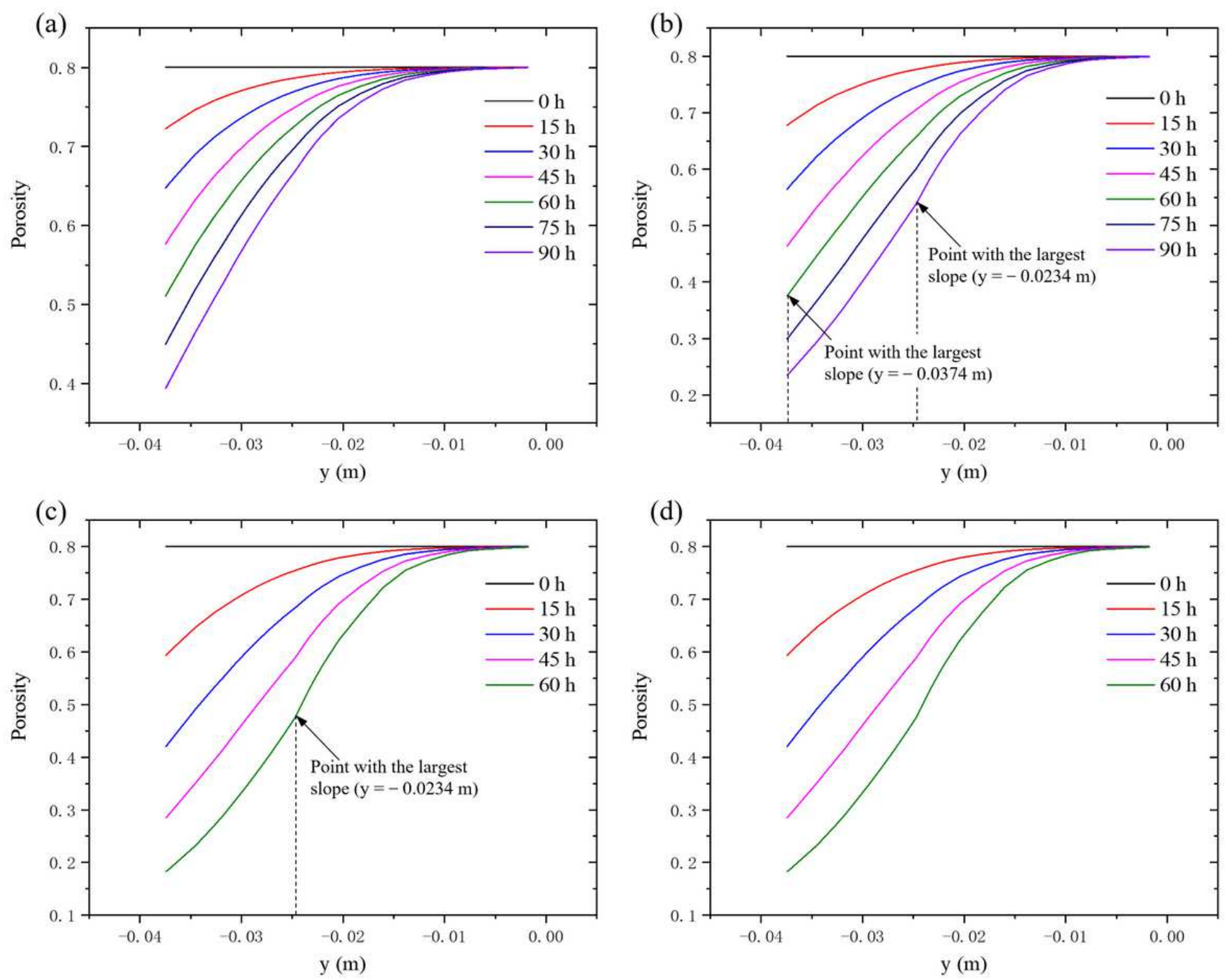

Figure 2

Porosity variations over time along line Iv under different inlet MTS concentration. (a) $0.086 \mathrm{~mol} / \mathrm{m3}$; (b) $0.136 \mathrm{~mol} / \mathrm{m3}$; (c) $0.186 \mathrm{~mol} / \mathrm{m3}$; (d) $0.236 \mathrm{~mol} / \mathrm{m} 3$. Ttop $=900 \mathrm{~K}$, Tbottom $=1150 \mathrm{~K}$, inlet velocity $0.0127 \mathrm{~m} / \mathrm{s}, \mathrm{A}$ in C out. 

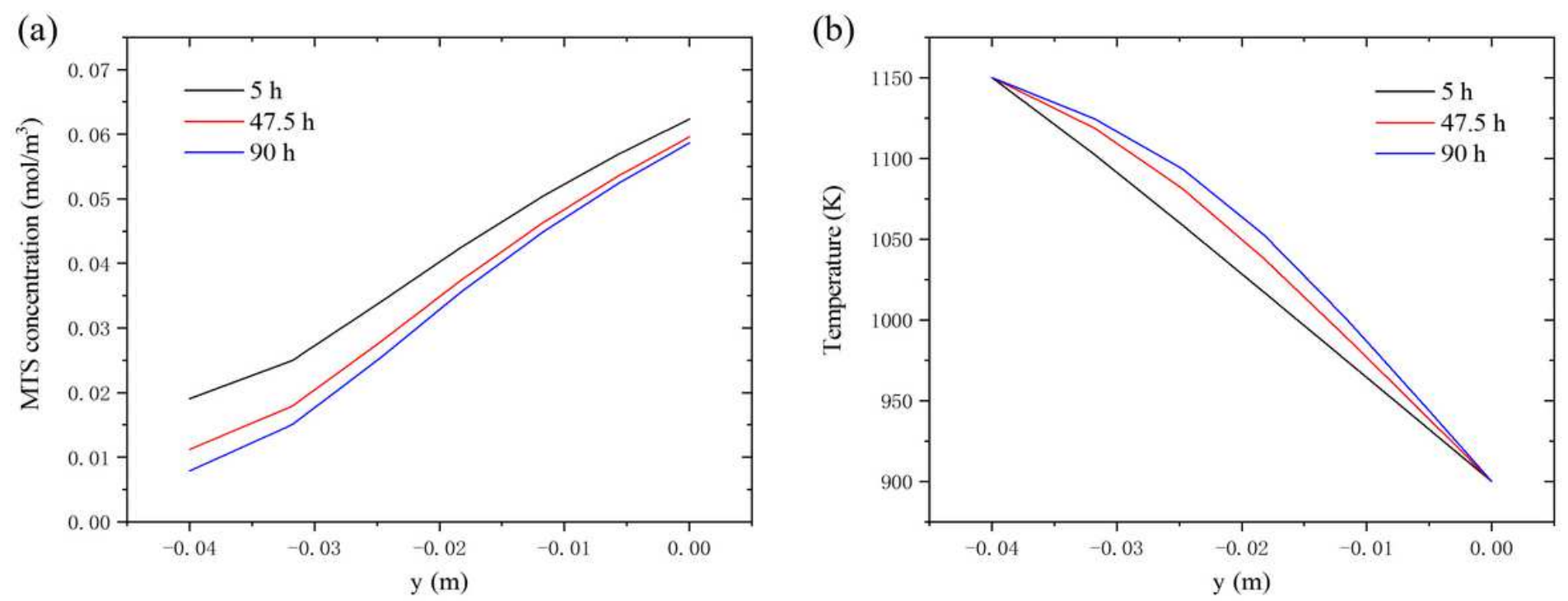

Figure 3

MTS concentration (a) and temperature (b) variations over time along line lv in the case of inlet MTS concentration $0.086 \mathrm{~mol} / \mathrm{m} 3$, Ttop $=900 \mathrm{~K}$, Tbottom $=1150 \mathrm{~K}$, inlet velocity $0.0127 \mathrm{~m} / \mathrm{s}, \mathrm{A}$ in C out.

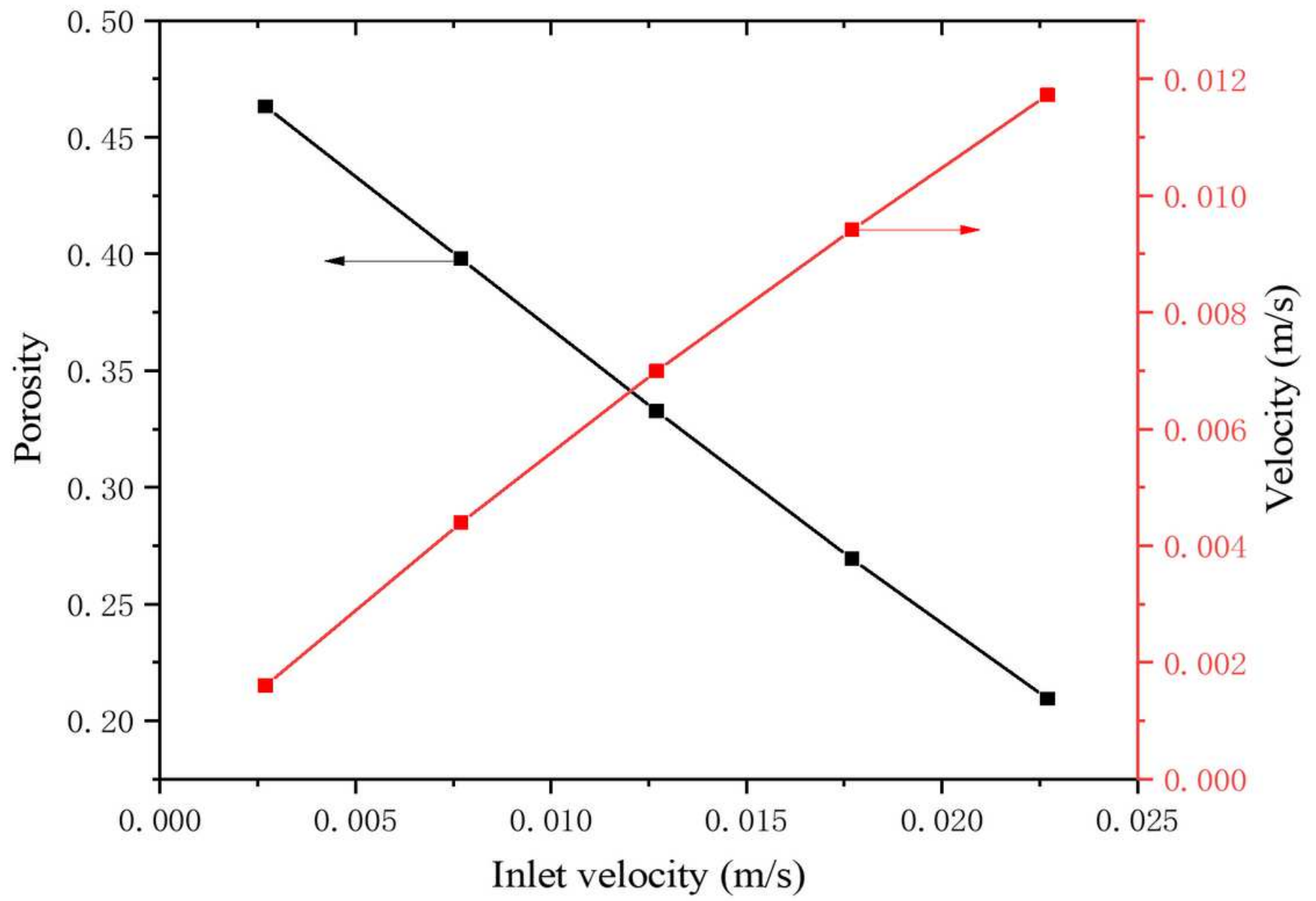


Porosity and velocity at the point $\mathrm{M}$ under different inlet velocity. Inlet MTS concentration $0.186 \mathrm{~mol} / \mathrm{m} 3$, Ttop $=900 \mathrm{~K}$, Tbottom $=1150 \mathrm{~K}, \mathrm{~A}$ in C out, infiltration time $\mathrm{t}=50 \mathrm{~h}$.
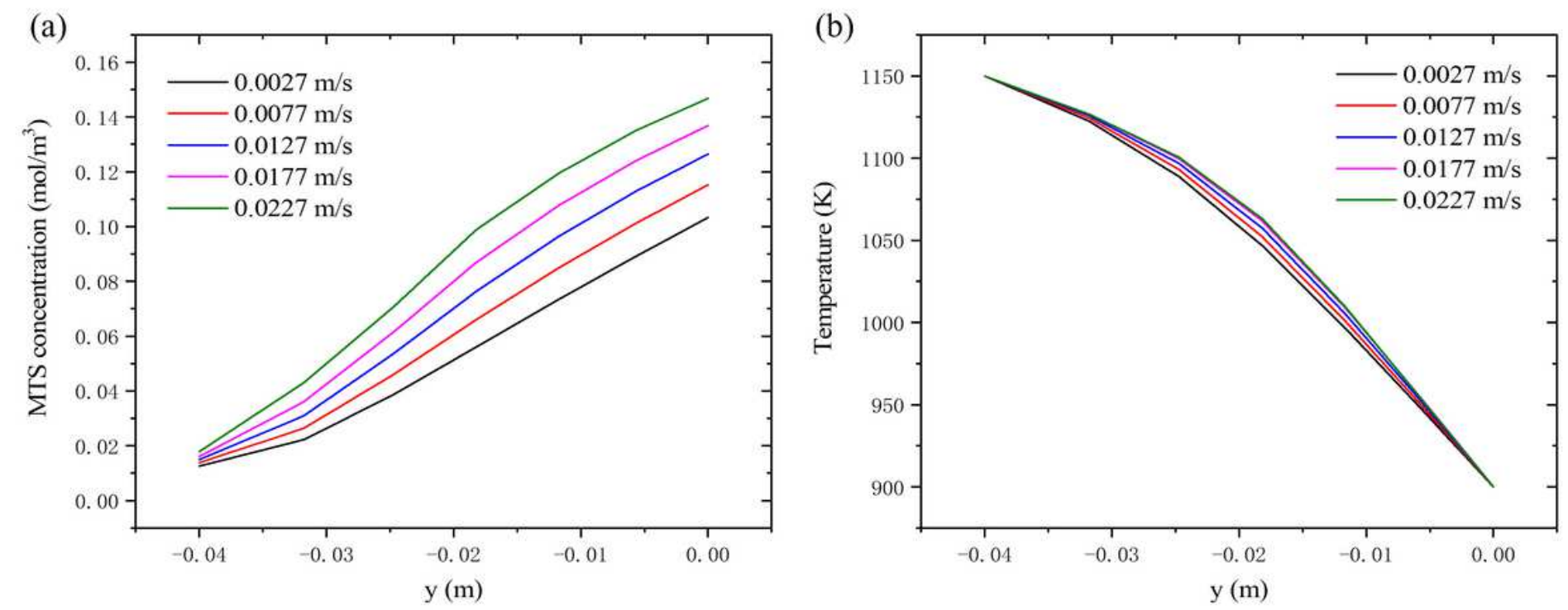

\section{Figure 5}

MTS concentration and temperature distribution along line Iv under different inlet velocity. Inlet MTS concentration $0.186 \mathrm{~mol} / \mathrm{m} 3$, Ttop $=900 \mathrm{~K}$, Tbottom $=1150 \mathrm{~K}, \mathrm{~A}$ in C out, infiltration time $\mathrm{t}=50 \mathrm{~h}$. 

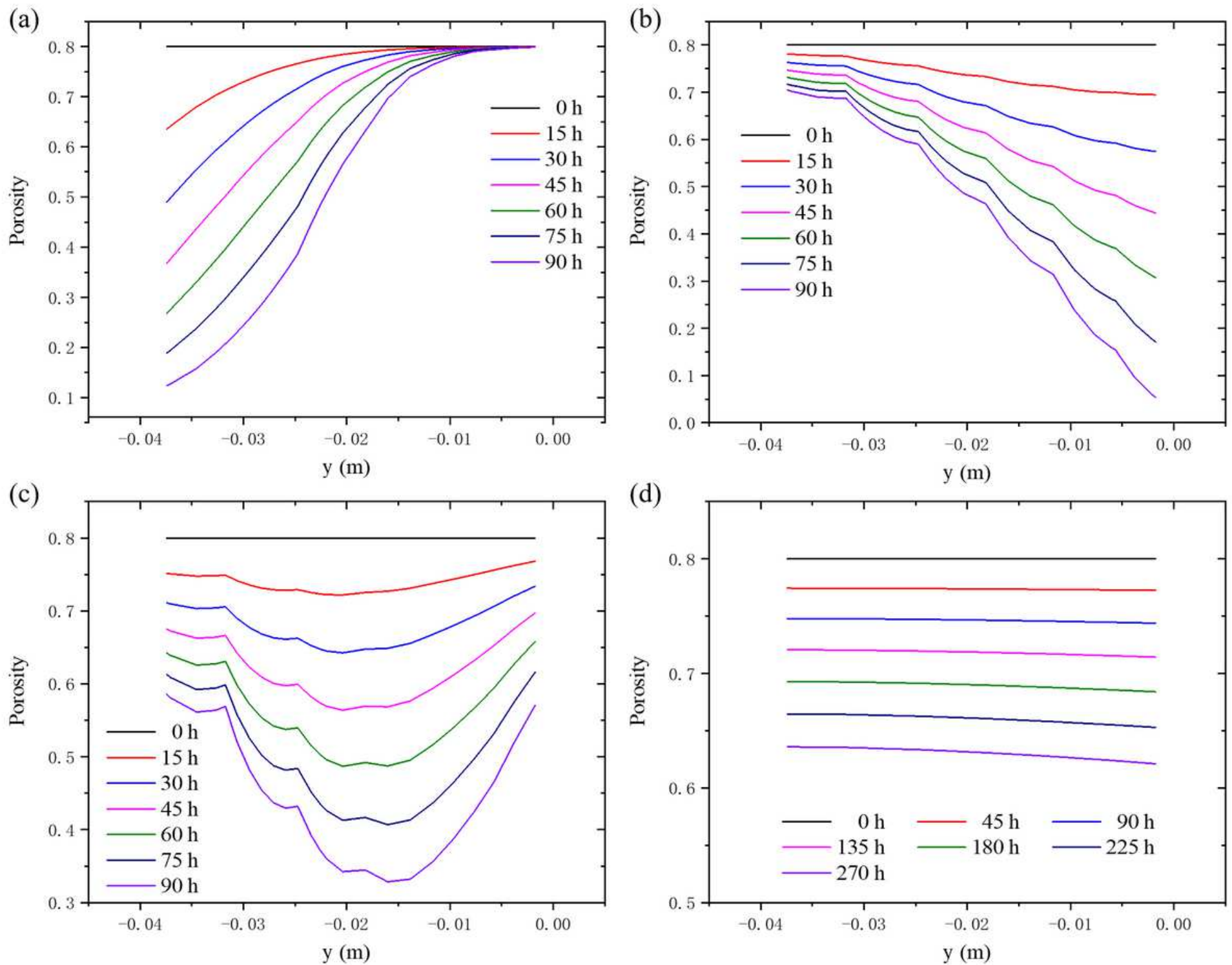

\section{Figure 6}

Porosity variations over time along line Iv under different temperature pairs. (a) Ttop $=900 \mathrm{~K}$, Tbottom $=$ $1150 \mathrm{~K}$; (b) Ttop $=1100 \mathrm{~K}$, Tbottom $=1200 \mathrm{~K}$; (c) Ttop $=1050 \mathrm{~K}$, Tbottom $=1200 \mathrm{~K}$; (d) Ttop $=1000 \mathrm{~K}$, Tbottom $=1000 \mathrm{~K} \mathrm{~mol} / \mathrm{m} 3$. Inlet MTS concentration $0.0186 \mathrm{~mol} / \mathrm{m} 3$, inlet velocity $0.0127 \mathrm{~m} / \mathrm{s}, A$ in C out. 


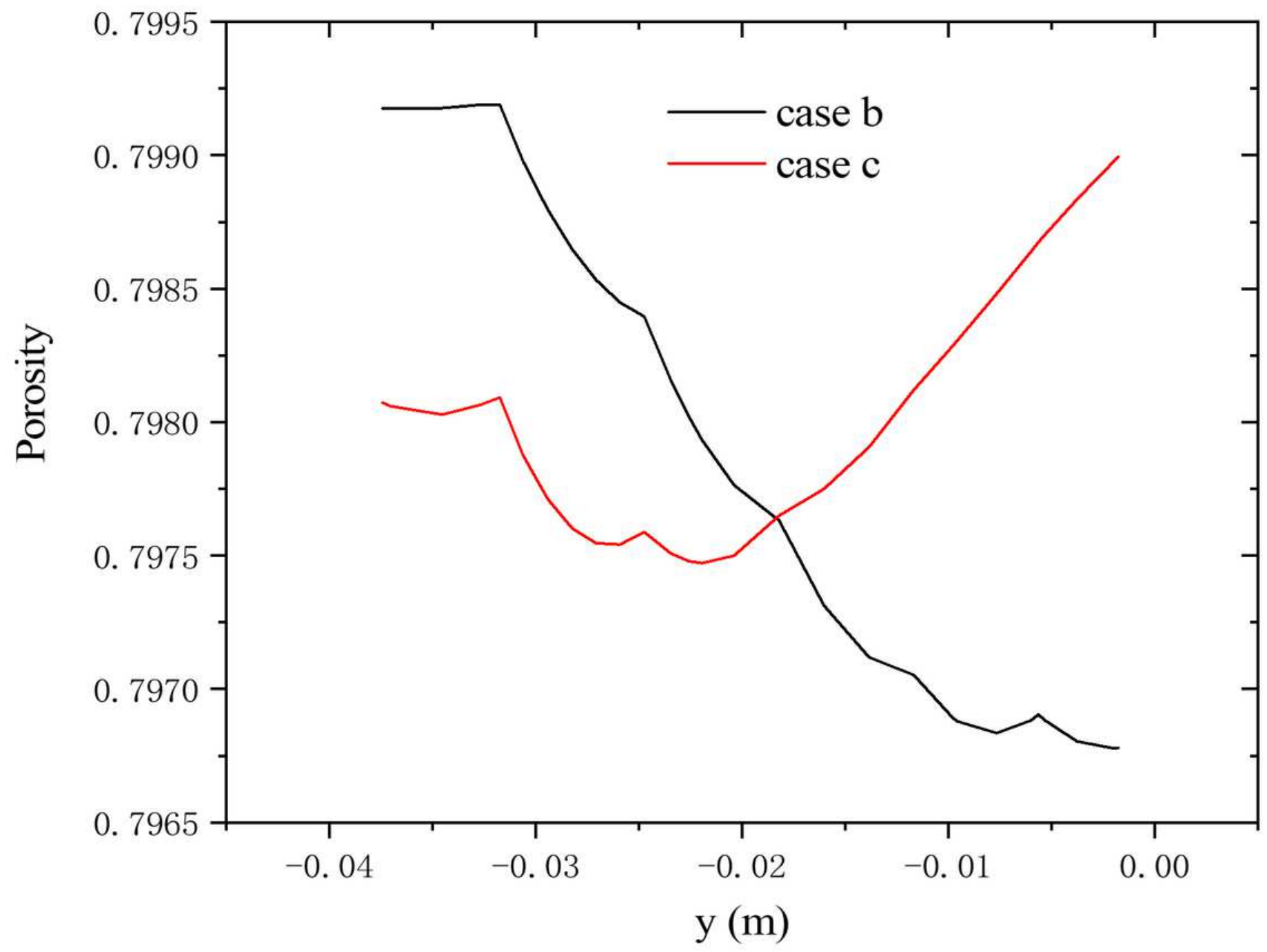

Figure 7

Porosity distribution in the case $b$ and $c$ at $t=1 \mathrm{~h}$. 


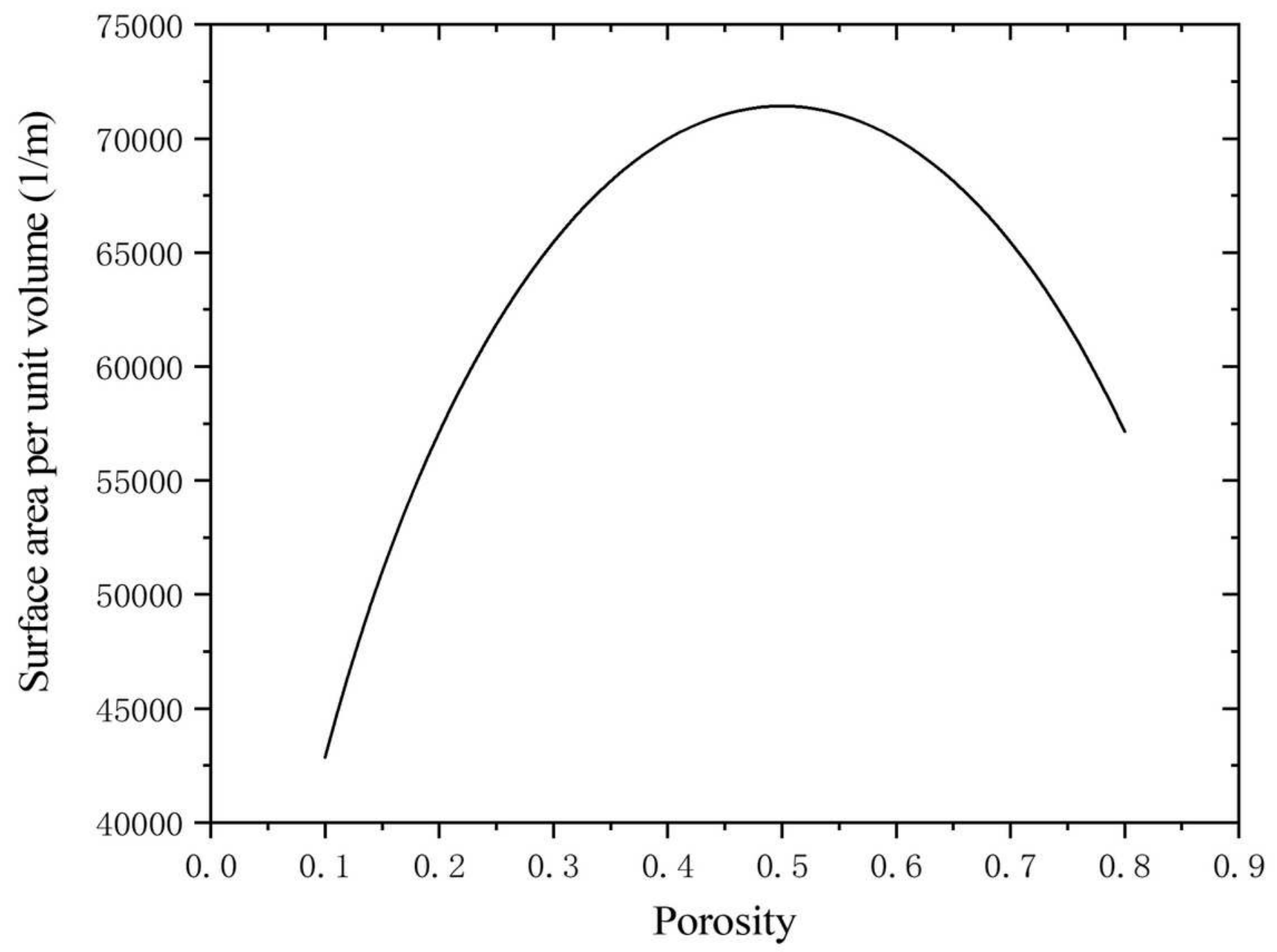

Figure 8

Relationship of surface area with porosity. 

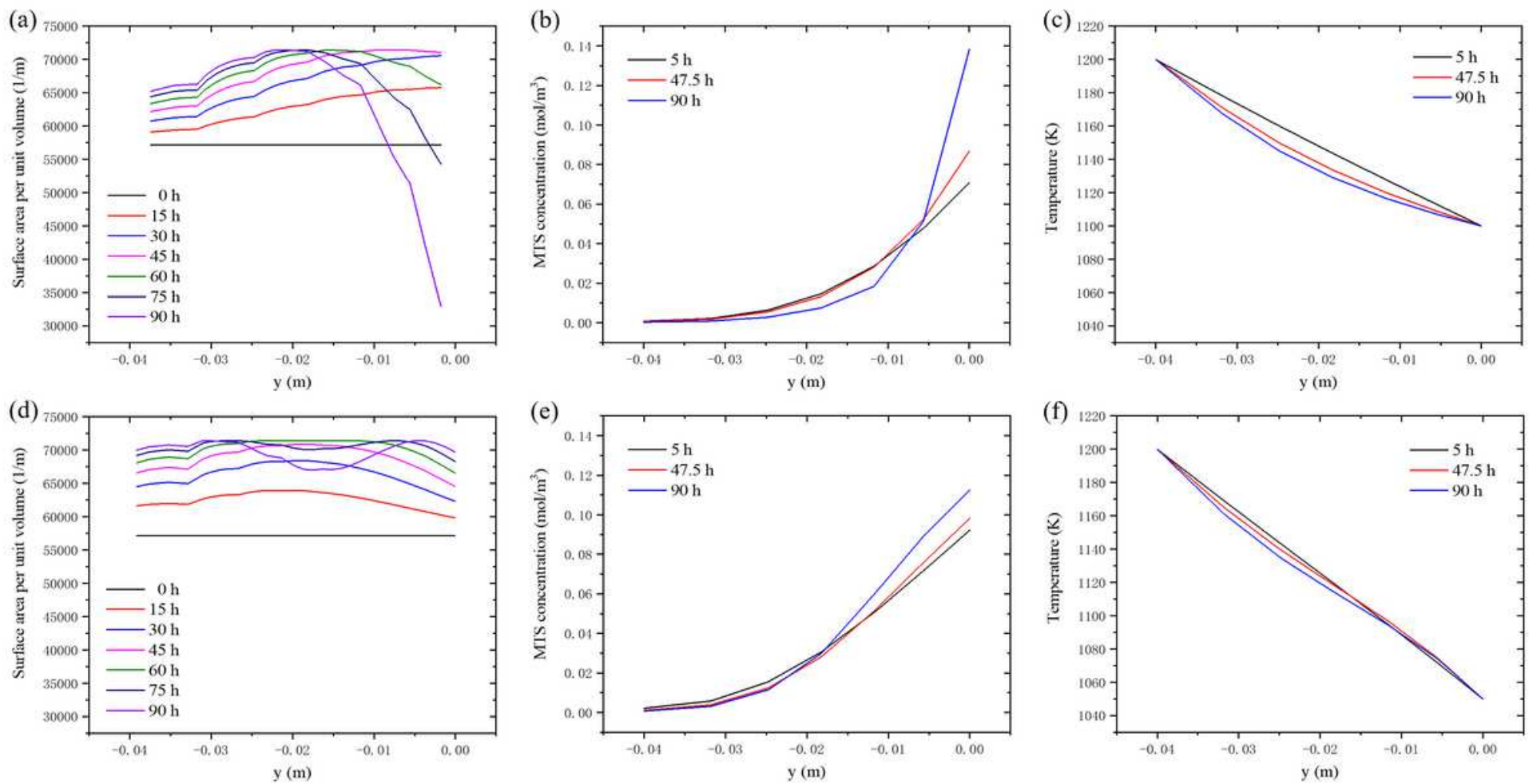

Figure 9

Surface area per unit volume, MTS concentration and temperature variations over time along the line Iv corresponding to the case $b(a-c)$ and the case $c(d-f)$.

(a)
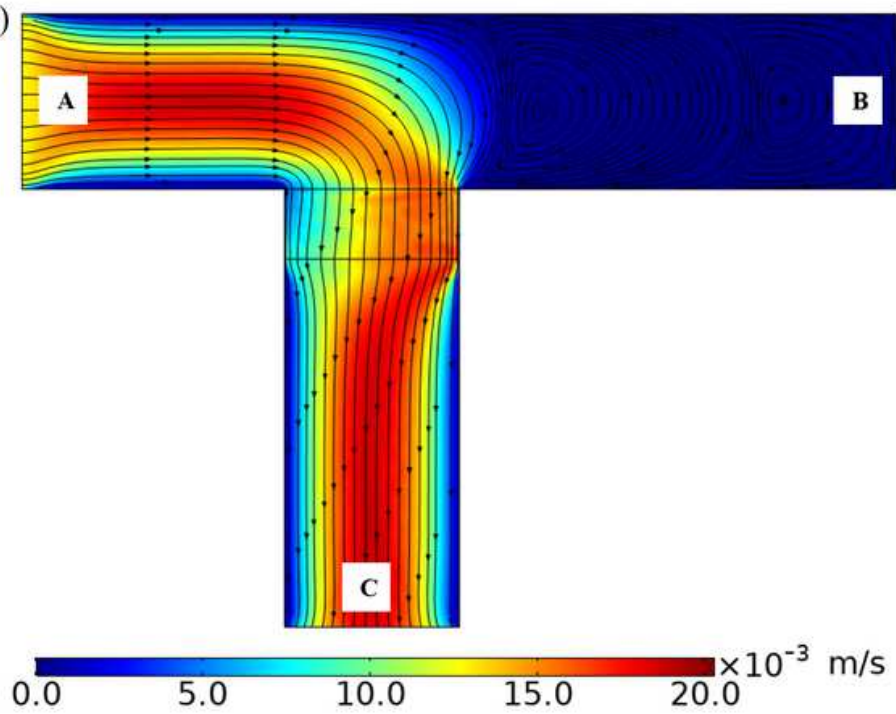

(b)
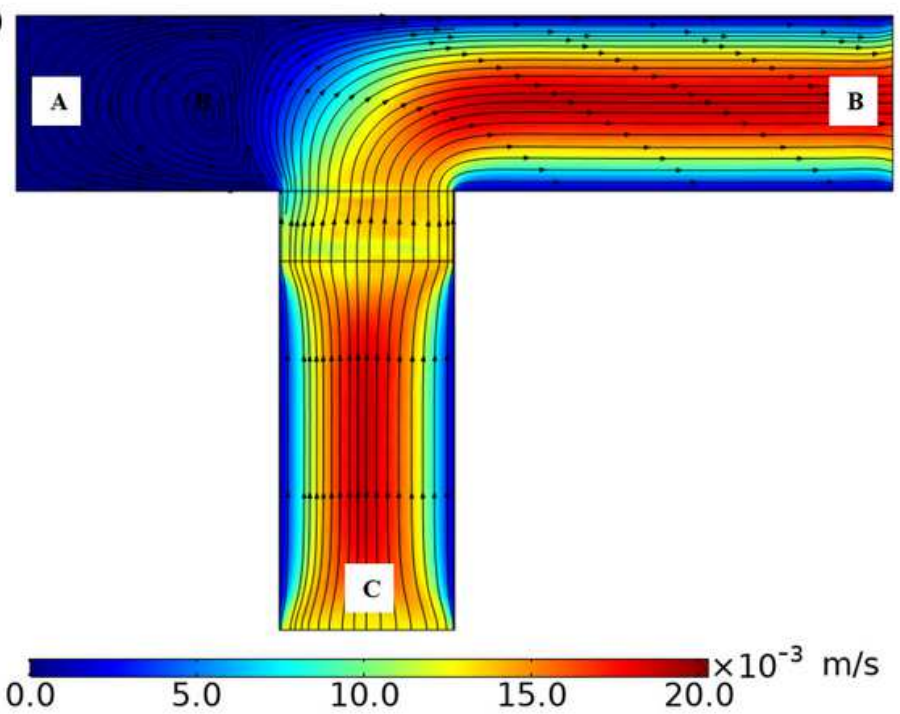

Figure 10

Streamlines distribution at the last hour of each step in a simple two-step densification scheme. The detailed parameters are listed in table 2 . The vectors give the direction, and the color gives the magnitude in $\mathrm{m} / \mathrm{s}$. 

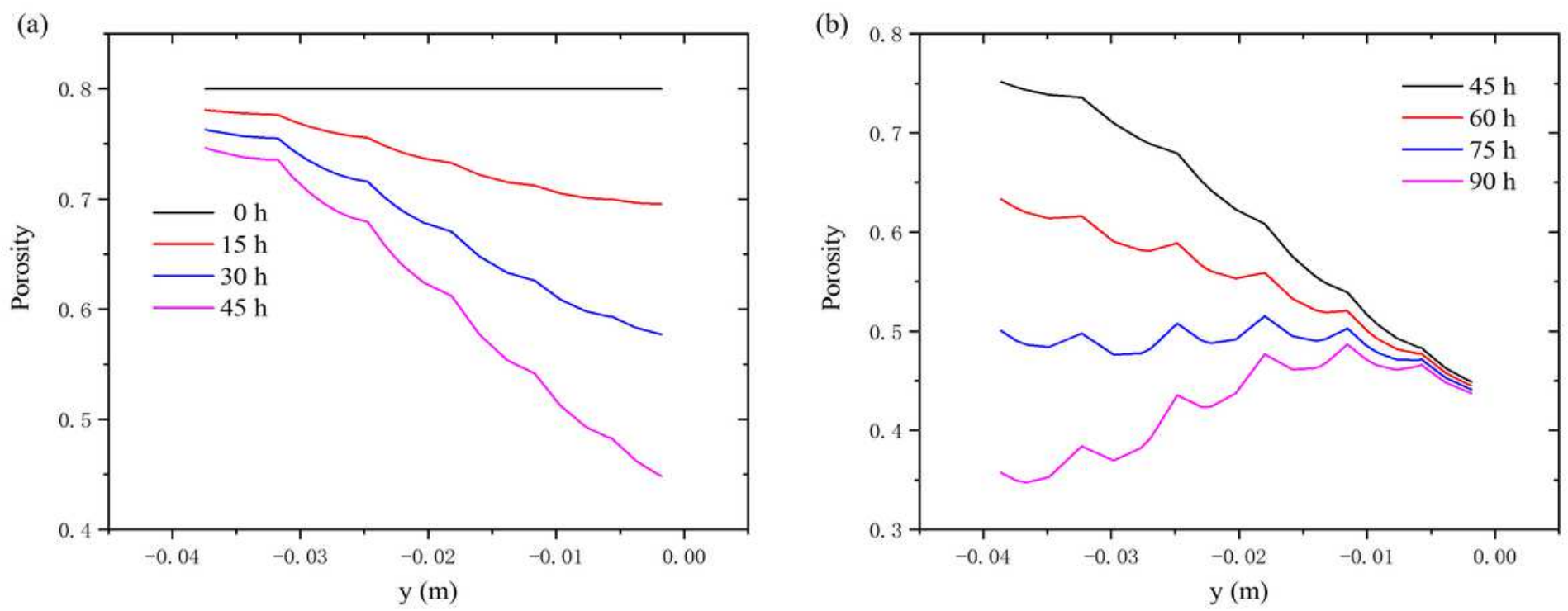

\section{Figure 11}

Porosity variations over time along line Iv in a simple two-step densification scheme. (a) - (b) Step I - Step II. The detailed parameters are listed in table 2.

(a)
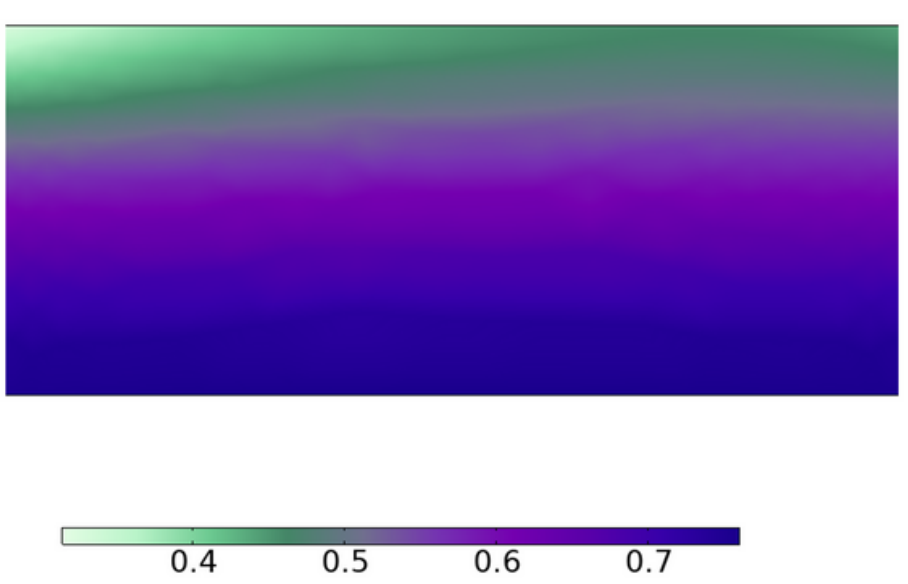

(b)

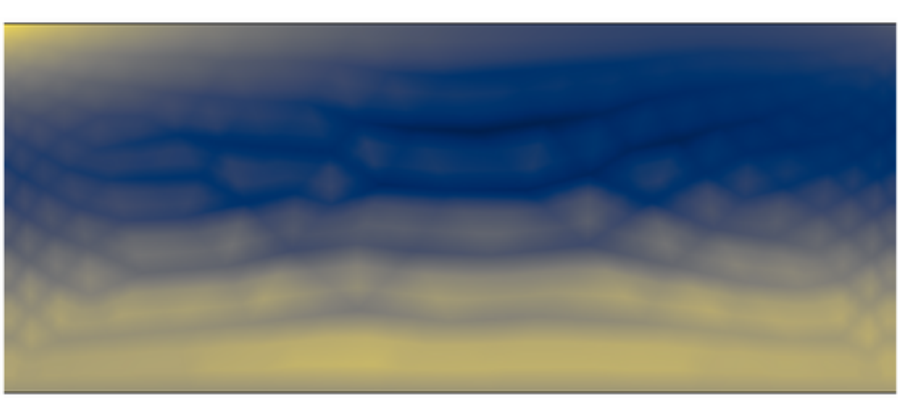

\section{Figure 12}

Contour of porosity variations over the whole preform at the last hour of each step in a simple two-step densification scheme. (a) - (b) Step I - Step II. The detailed parameters are listed in table 2. Porosity in the two steps differs a lot, for the convenience of viewing, different bars and color systems were used in the porosity contours. 
(a)

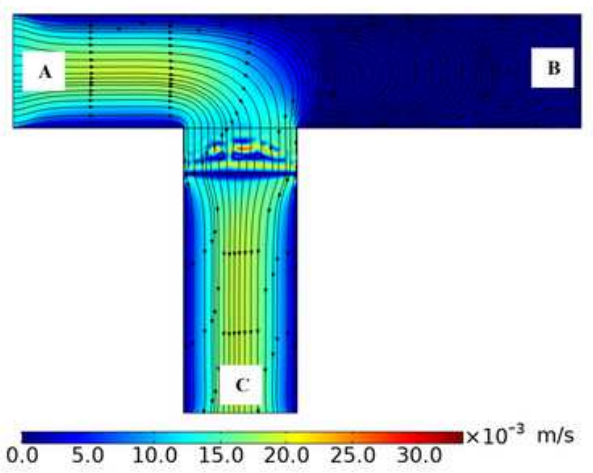

(d)

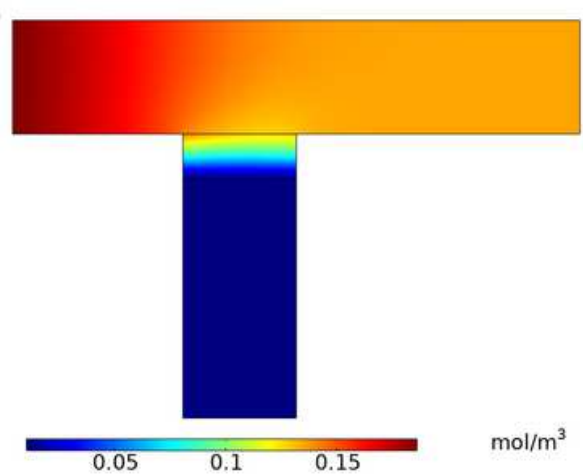

(b)

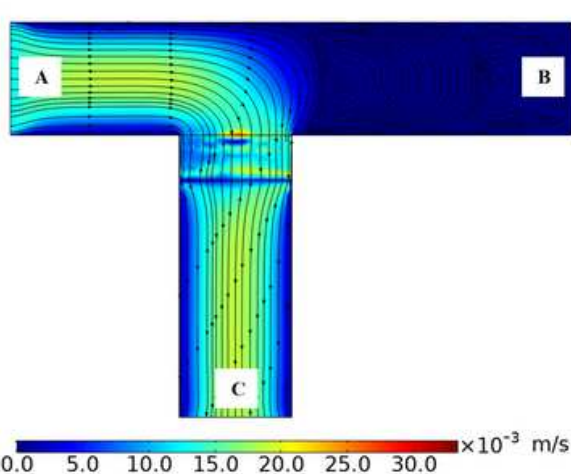

(e)
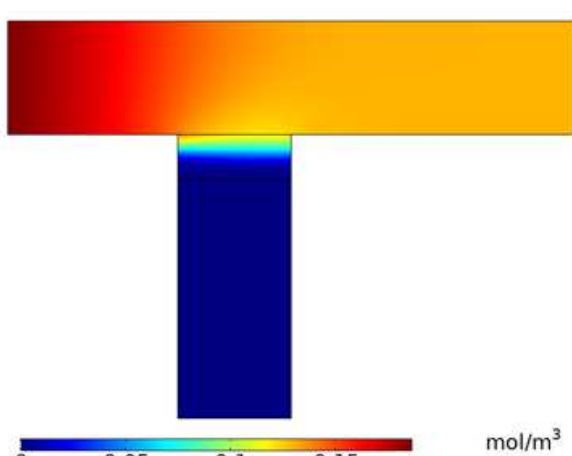

$\mathrm{mol} / \mathrm{m}^{3}$ c)

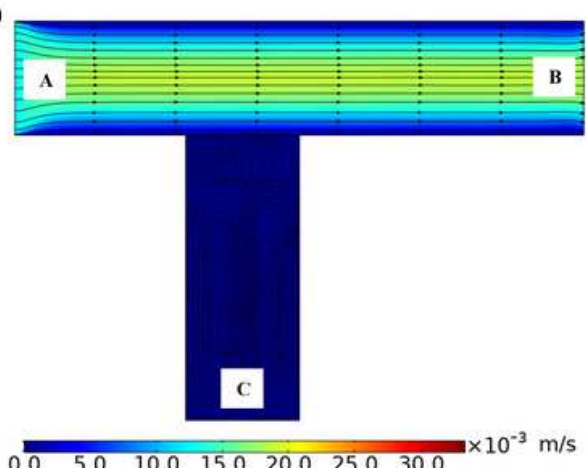

(f)

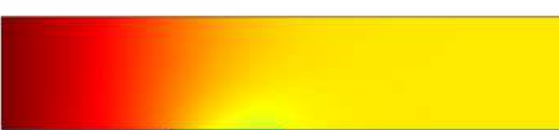

0.05
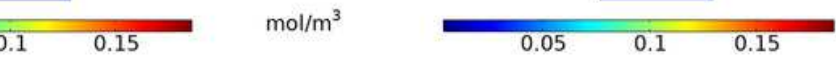

$\mathrm{mol} / \mathrm{m}^{3}$

Figure 13

Streamlines (a-c) and MTS concentration (d-f) distribution at the last hour of each step in the three-step densification scheme. The detailed parameters are listed in table 3 . The vectors give the direction, and the color gives the magnitude in $\mathrm{m} / \mathrm{s}$ or $\mathrm{mol} / \mathrm{m} 3$.
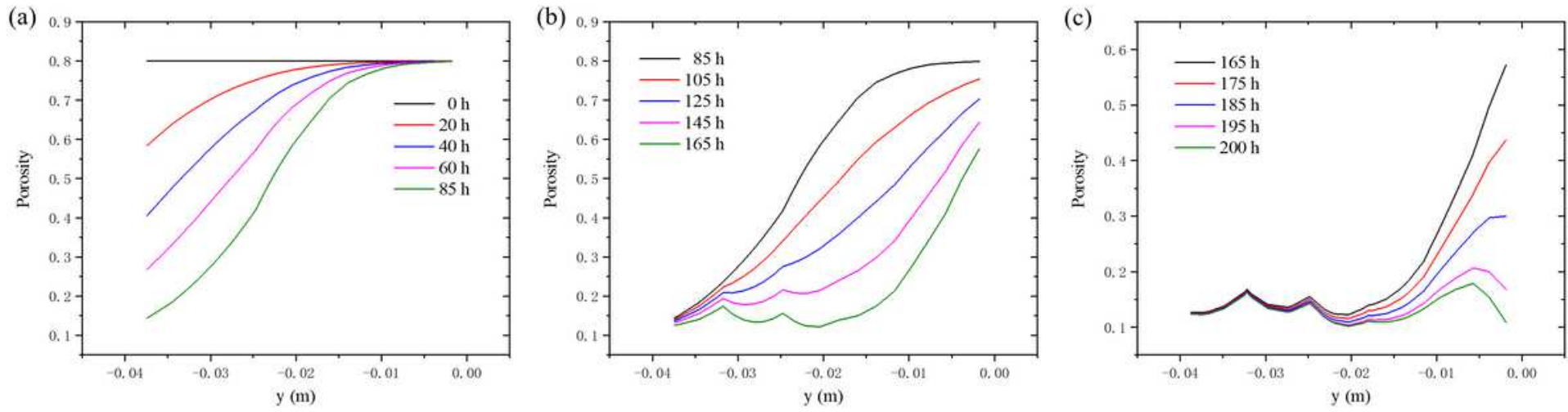

Figure 14

Porosity variations over time along line IV in a three-step densification scheme. (a) - (c) step I - step III. The detailed parameters are listed in table 3. 
(a)
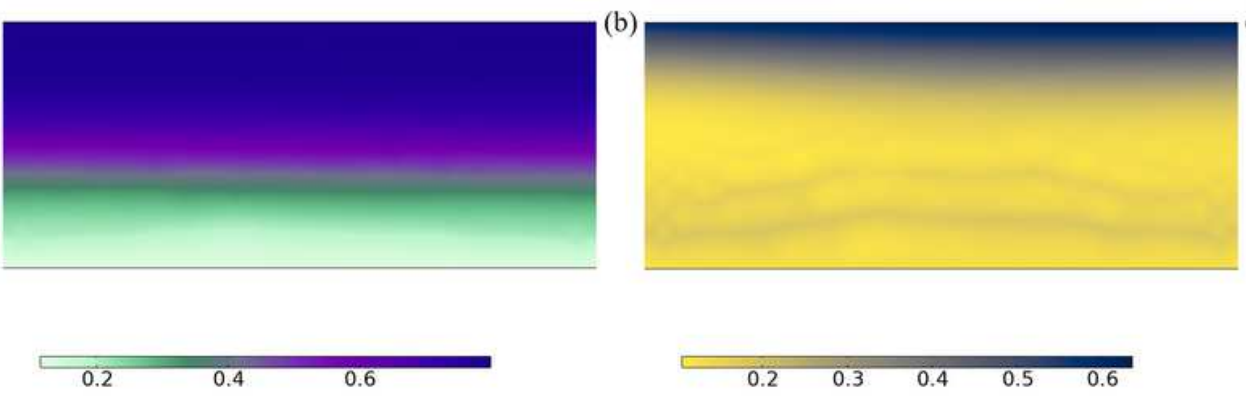

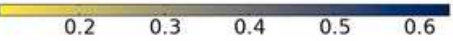

(c)
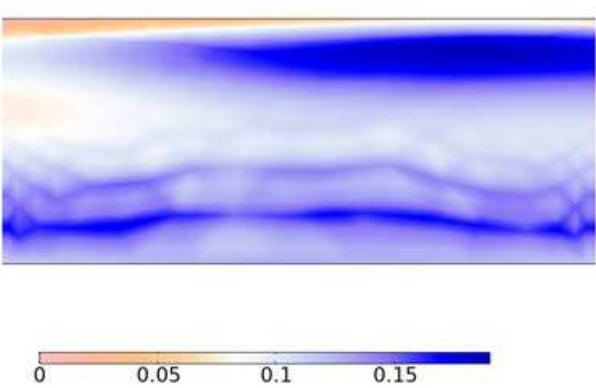

\section{Figure 15}

Contour of porosity variations over the whole preform at the last hour of each step in the three-step densification scheme. (a) - (c) Step I - Step III. The detailed parameters are listed in table 3.

(a)

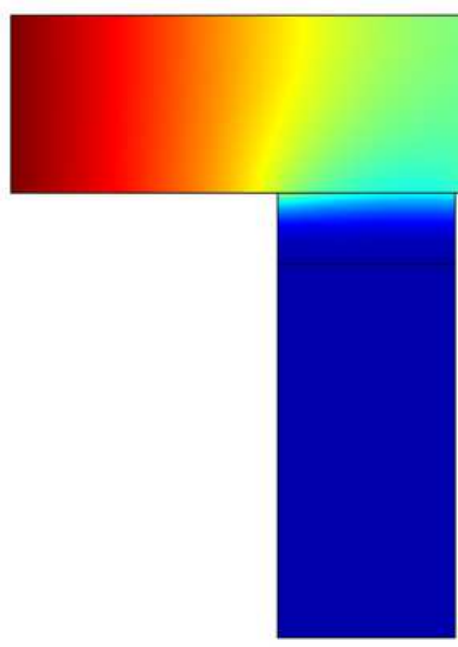

0

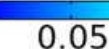

0.15 (b)

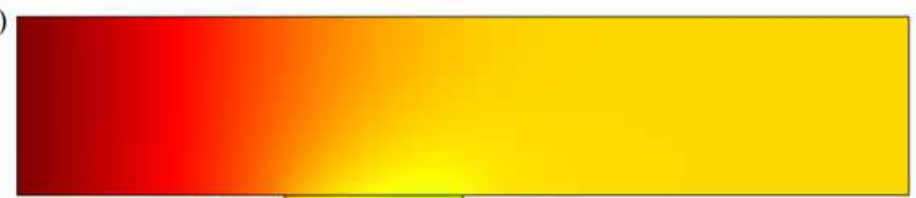

$\mathrm{mol} / \mathrm{m}^{3}$

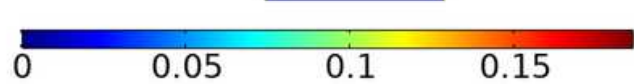

$\mathrm{mol} / \mathrm{m}^{3}$

\section{Figure 16}

Contour of MTS concentration distribution at $t=1 \mathrm{~h}$ under different outlet condition. (a) A in B out; (b) A in, $B$ and $C$ out.

(a)
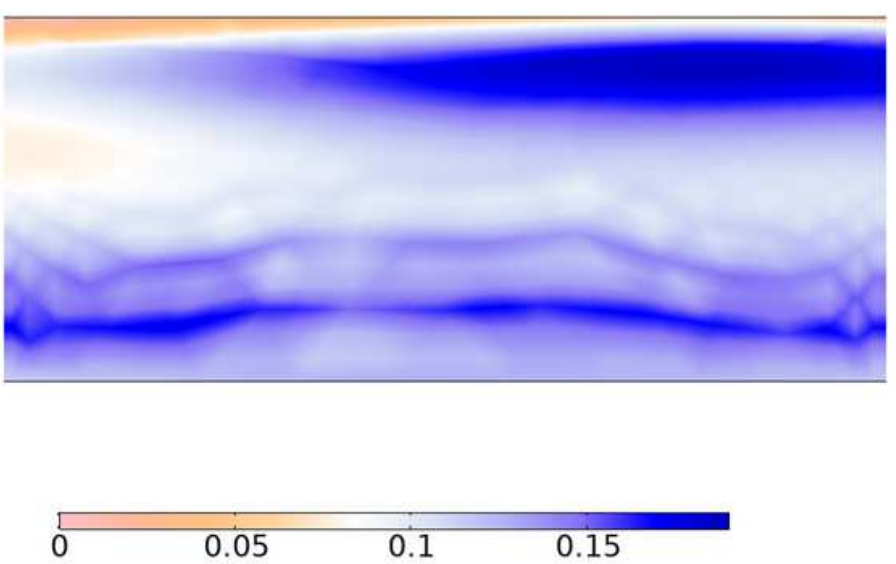

(b)
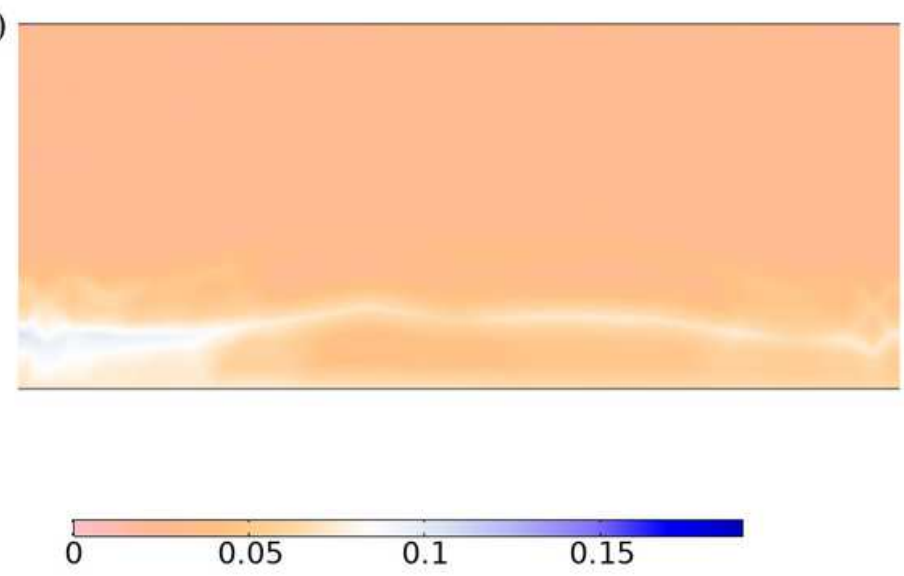
Contour of porosity distribution (a) before and (b) after some improvements being taken in the three-step densification scheme. 